\title{
Demographic consequences of HIV
}

\author{
Martin Karlsson • Stefan Pichler
}

Received: 27 March 2013 / Accepted: 21 January 2015 /

Published online: 13 February 2015

(C) Springer-Verlag Berlin Heidelberg 2015

\begin{abstract}
In this study, we estimate the effect of the HIV epidemic on demographic outcomes in three countries in Sub-Saharan Africa. We apply the synthetic control group method and estimate the consequences for life expectancy, mortality, and birth rates. According to standard measures of fit, the method seems to perform well for all countries and outcomes. Our results show a large effect on life expectancy and mortality in two countries, and a small and insignificant effect on birth rates. The impact of the pandemic is very heterogeneous. In Mozambique, the impact of HIV on life expectancy and mortality appears to have been surprisingly small. This heterogeneity is not due to AIDS causing fewer deaths in Mozambique than in the two other countries. Instead, the net effect of HIV in Mozambique appears to be diminished by reduced mortality for other causes - in particular child mortality, respiratory infections, and injuries.
\end{abstract}

Keywords HIV · AIDS · Mortality $\cdot$ Life expectancy $\cdot$ Fertility $\cdot$ Synthetic control groups

JEL Classification $\mathrm{I} 15 \cdot \mathrm{J} 11 \cdot \mathrm{O} 15$

Responsible Editor: Junsen Zhang

M. Karlsson

CINCH, University of Duisburg-Essen, Schützenbahn 70, 45127 Essen, Germany

e-mail: martin.karlsson@uni-due.de

S. Pichler $(\bowtie)$

ETH Zurich, KOF Swiss Economic Institute, Leonhardstrasse 21, 8092 Zurich, Switzerland

e-mail: pichler@kof.ethz.ch 


\section{Introduction}

The HIV pandemic represents one of the worst demographic and economic shocks to hit the world in the past century. It is now 30 years since this formerly unknown disease was recognised, and still the effects on the economy have not been completely understood.

Many papers estimate the impact on economic growth and results vary widely. While some studies find quite large negative effects (see for instance Gaffeo 2003, who estimates a reduction in the yearly growth rate of 1.2-1.7 percentage points), other studies, like Bloom and Mahal (1997), find no effects, while Young (2005) even predicts positive effects. This ambiguity might result from effects working through many different channels and different channels dominating in different countries.

In this study, we analyse the impact of the HIV/AIDS pandemic on demographic variables for three countries in the Sub-Saharan region. Even if HIV is normally associated with elevated mortality, it is far from obvious how it affects various demographic variables. Increasing our knowledge about the demographic impact-which represents one out of several mechanisms by which the pandemic may have repercussions on the economy-we may achieve a better understanding of its overall impact on society and on the economy in affected societies. For example, Young (2005) suggests that HIV leads to a reduction in fertility and therefore represents a "gift of the dying" which fosters economic growth for future generations. In order to assess the validity of this claim it is important to obtain a clear estimate of the effects of HIV on fertility. ${ }^{1}$

Since HIV/AIDS is a lethal disease, a substantial disruption of demographic variables such as life expectancy and the mortality rate can be expected. A clean estimate of the causal impact is complicated by the fact that important secular trends in several demographic variables were present before the pandemic hit. Moreover, life expectancy in African countries is quite low compared to other countries at a similar level of development. Therefore, it is important to assess how much of the difference is due to HIV and to which degree other conditions are responsible.

In addition, HIV will very likely change incentives for engagement in sexual activity and thus there might also be an effect on fertility. However, different purported mechanisms lead to different predictions about the effect. On the one hand, women who know about their infection status might not want to infect their partners and future children and thus fertility could be reduced. Moreover, there exists evidence that HIV affects fertility biologically through increased rates of miscarriage and stillbirth (see for instance Fabiani et al. 2006). On the other hand, HIV might also lead to positive effects on the birth rate. Chen (2010) suggests that higher life expectancy in general leads to a decreased fertility since parents might prefer to concentrate their investments on fewer children. HIV might reverse this pattern since the decrease in

\footnotetext{
${ }^{1}$ Several later studies_-such as Kalemli-Ozcan (2012)_rebut the main result of Young (2005). However, in this paper, we combine the analysis with other demographic variables in order to obtain a deeper understanding of the processes.
} 
life expectancy might lead to an increase in fertility. Estimating the effect of HIV on fertility helps to identify which mechanism prevails.

This paper is the first to consider the three outcome-variables life expectancy, death rates and birth rates. Other papers with a demographic focus concentrate on direct effects and thus estimate the effects on mortality and life expectancy (see, for instance, the publication of the UN Population Division 2004). A second often considered relationship is the behavioural effect on fertility (see Kalemli-Ozcan 2012 for a recent study on this topic). Analysing both direct and indirect demographic effects together is useful because they are interrelated. The observation made by Chen (2010), with lower life expectancy leading to higher fertility, can only hold true if there is in fact a large enough drop in life expectancy.

We focus on the effects of HIV/AIDS in three heavily affected countries. To overcome difficulties of standard comparative case studies, we use a novel empirical approach based on Abadie and Gardeazabal (2003). According to standard measures of fit, the method seems to perform well for all three outcomes and for all three countries we consider. Our results show a large effect on life expectancy and mortality for two countries, and a small and insignificant effect on birth rates. Thus, there is substantial heterogeneity between the countries in terms of the impact of the pandemic. In Mozambique, the impact of HIV on life expectancy and mortality appears to have been surprisingly small.

The paper is structured as follows: First, an overview of the historical development of HIV and its impact on demographic factors will be given. In Section 3, the synthetic control method for comparative case studies of Abadie and Gardeazabal (2003) will be presented and discussed, followed by the description of the data and variables used in Section 4. The results are presented in Section 5. Finally, an evaluation of the achieved results will be given in Section 6 .

\section{Background and literature review}

There is general agreement in the literature that the HIV pandemic started in Africa and then spread globally. The first published scientific account of HIV was made in 1981 by the Centre for Disease Control and Prevention in the USA (see, for instance, Iliffe 2006 on the historical development). According to the UNAIDS report of 2013 (UNAIDS 2013), approximately 35 million people were infected worldwide in 2012, 2.3 million people are newly infected each year and 1.6 million people pass away every year due to HIV infection. By 2007, a cumulative total of 24 million people had died from AIDS, and by 2030 this cumulative total is predicted to reach 75 million (Bongaarts et al. 2010). While the developed countries managed to contain the threat created by HIV/AIDS, less developed and developing countries were hit hard by the disease and are still suffering from this shock. The Sub-Saharan region, especially, became the global centre of this disease, with around 1.6 million newly infected in 2012 and 1.3 million dying each year (UNAIDS 2013).

The estimated HIV prevalence rate in Sub-Saharan Africa for 2012 was $4.6 \%$. Women are generally more strongly affected than men, with the proportion of HIVinfected individuals being $56 \%$ female (The World Bank 2011). Considering the 
shock caused by HIV/AIDS, one question remains: Why were different regions affected differently? Bloom et al. (1998) addressed the problem, not only considering the high HIV/AIDS prevalence rate but also the general economic and social situation of the whole region. They argue that the geographic location of these countries in the tropics represents their main disadvantage. Due to the climatic conditions of this area, it is a hotbed for all kinds of diseases such as malaria, which consequently leads to lower life expectancy and higher health care costs. Additionally, most of the area is not usable for intensive agricultural production, and, last but not least, this area is far away from the North American and European markets and the emerging Asian market. Bloom et al. (1998) therefore argue that the reason for the dire economic situation of Sub-Saharan Africa is related to its climate and geography and-connected with these factors - to the demographic structure and availability of health care. Although HIV/AIDS is not directly related to the tropical climate, they argue that due to the rapid urbanization the disease was spread fast as a result of disbanded social relations.

There is a longstanding debate in economics on how health, mortality and living standards are related to each other. The increase in life expectancy in England and Wales throughout the nineteenth and twentieth century was driven by a decline in mortality rates as a result of improved medical care and consequently improved health (Cutler et al. 2006). This increase in life expectancy was therefore strongly associated with economic growth even though the relationship between the two variables is a complex and dynamic one (Fogel 2004; Deaton 2008). Chen (2010) shows in a theoretical model that a higher life expectancy will in general lead to a decline in the fertility rate and a higher educational level due to a quality-quantity trade-off concerning the number of children and their education. There is, however, a possible steady-state where a country is caught in a "poverty trap" characterised by high fertility rates, low educational level and low life expectancy. Becker et al. (1990) also consider two steady-states, where one equilibrium is characterised by a low fertility rate, increasing investments in education and physical capital and the second steadystate is found with a high fertility rate and consequently low investments in human and physical capital. This is referred to as the "Malthusian" equilibrium, which can only be changed with a strong investment policy. The fertility rate, the mortality rate and the general level of education are decisive factors for life expectancy (cf. Becker et al. 1990). Even if it is not known exactly how these determinants contribute to changes in life expectancy, it is likely that an external shock to the mortality rates-as in the case of HIV-would have an impact on all the other variables.

Several studies consider the relation between demographic variables, such as the fertility rate, and the HIV prevalence rate. Fortson (2009) reports only a small effect of HIV/AIDS prevalence rates on fertility rates when comparing 12 different SubSaharan countries. She argues, however, that if educational levels are taken into account, the relation between HIV/AIDS prevalence rates and fertility becomes evident. Fink and Linnemayr (2008) also consider how education mediates the effect of HIV on fertility. They find a weak and statistically insignificant positive overall correlation between the HIV/AIDS prevalence rate and the fertility rate. If one differentiates by educational levels, the pandemic has a positive effect on fertility in the lowest educational groups. On the other hand, there is a negative effect 
of HIV/AIDS on fertility of mothers with secondary schooling and higher education. Durevall and Lindskog (2011) also investigate the effect on fertility in Malawi and find mixed results. They find a relation between the age of mothers and their desired number of children. Their study shows that younger women increase their desired number of children while older women decrease it. The exact mechanism cannot be identified, but it is believed to be the desire to avoid giving birth to HIV-infected children. Moreover, (Young 2005, 2007) identifies a large negative effect of the epidemic on fertility, whereas other studies (Kalemli-Ozcan 2012; Juhn et al. 2013; Shapira 2013) report much smaller or even positive effects. Summing up, there is remarkable disagreement as to the effects of HIV on fertility (Durevall and Lindskog 2011).

A related topic is how investment in human capital is affected by HIV/AIDS prevalence rates. Since there is a strong correlation between fertility rates and educational attainment, several studies focus on the role of education with respect to HIV/AIDS prevalence rates. Fortson (2011) finds that the HIV/AIDS prevalence rate is directly negatively correlated to years of school attendance. Her analysis shows that a prevalence rate of $10 \%$ lowers the number of years of school attendance by 0.5 years. She argues that the lower investment in human capital is a consequence of the higher mortality risk and the associated drop in investment.

A further parameter which is obviously affected by the HIV pandemic is the mortality rate. In 2012, about $2.7 \%$ of all deaths worldwide were caused by AIDS (World Health Organization 2014). While in most parts of the world, this fraction was around $1 \%$; it was $15 \%$ in Sub-Saharan Africa. An even more drastic picture emerges if one takes a look at age groups. Amongst adults aged 15-59, the dominant cause for death in Sub-Saharan Africa in 2003 was AIDS (e.g. $85 \%$ in Botswana and $61 \%$ in Uganda). The group of adults between 15 and 59 years additionally makes up for $86 \%$ of all AIDS victims in 2007 (Bongaarts et al. 2010). This age profile, and its consequences for the workforce, has dramatic consequences for the economic development of the Sub-Saharan region.

However, it needs to be emphasised that even the impact on mortality rates and life expectancy is unclear. Even if the affected countries had vital statistics of a quality similar to those in developed countries, such that each death could be unambiguously attributed either to HIV or to other causes, estimating the impact of the disease would still represent a considerable empirical challenge due to the missing counterfactual. Health hazards like pandemics typically affect the frailest members of a societyeven after controlling for observable characteristics such as age and gender. Taken to its extreme, this form of selective mortality represents a "harvesting effect" such that victims of the health shocks are individuals who would have had a very short life expectancy also in the absence of the shock-which leads to a risk of seriously overestimating the effect of the pandemic (Fung et al. 2005). However, it could be argued that, when the HIV pandemic is concerned, selection should work in the opposite direction. Since young and healthy adults are more likely than others to engage in risky behaviour, there is reason to believe that the pandemic exhibits positive selective mortality, just as the 1918 influenza pandemic did (Gregson et al. 2006; Karlsson et al. 2014). 
A further demographic variable which complicates the picture is migration. Traditionally, migration has been studied as a variable which may explain the spread of disease. The role of migration within the context of the AIDS pandemic has been discussed by Ellis and Muschkin (1996), Decosas and Adrien (1996), Lurie (2006), Soskolne and Shtarkshall (2002), and Booysen (2006). Less attention has been devoted to migration as avoidance behaviour, despite evidence of its historical importance (McNeill 2010). Recent theoretical contributions by Mesnard and Seabright (2009) suggest that people who migrate to avoid an epidemic differ in important respects from the population left behind. Whenever migration is responsible for the spread of the disease, it will be a confounding factor which can possibly bias estimates. When, on the other hand, migration flows are triggered by the disease, they represent one out of many effects of the epidemic. Since this type of migration affects the denominator of several other demographic variables, it needs to be taken into account when assessing the impact of the pandemic on these other variables. It should be noted, however, that migration flows between Sub-Saharan Africa and other countries is limited. For example, the total stock of immigrants from Sub-Saharan countries in OECD countries was around 3.9 million in 2002, working out at less than $0.5 \%$ of the total population (OECD 2005). The migration flows between African countries have been somewhat larger. For example, the UNDP estimates that the total immigrant stock in South Africa was 1.0 million in year 2000, working out at around $2 \%$ of the population. This stock of migrants included large groups of immigrants from Mozambique $(260,000)$ and Zimbabwe $(127,000)$ (UNDP 2013).

\section{Study design}

In this paper, we contribute to the existing literature by using a relatively novel method which was introduced by Abadie and Gardeazabal (2003). The idea is that a combination of donor units in a comparative case study-a "synthetic control"provides better comparison data for the exposed unit than any single donor unit could do on its own. This method has three main advantages: firstly, the synthetic control group is calculated using a data-driven algorithm which does not allow for subjective choices of the researcher. Secondly, pre-intervention similarities of the synthetic control group and the exposed unit are explicitly quantified. Finally, the relative contribution of each donor unit is shown and restricted to be non-negative (Abadie et al. 2010). Abadie and Gardeazabal (2003) used this method to estimate the effect of terrorism on GDP per capita in northern Spain and the effect of a Californian antitobacco law in 1988 on cigarette consumption (Abadie et al. 2010). Examples of other studies using this method are Hinrichs (2012) who studies the effects of affirmative action bans on minority students, or Montalvo (2011) studying the effects of terrorism on voting behaviour.

In the current setting, finding a suitable control group represents a considerable challenge, for several reasons. Firstly, HIV affected a geographically concentrated group of countries in Sub-Saharan Africa, which arguably have a very special history compared to other regions of the world. Therefore, we first restrict our analysis 
to African countries, in order to get maximum comparability between treated and control cases. Since most countries in this region were affected, it is not an easy task to find potential donors unaffected by HIV, and our estimates in this part will thus inevitably be based on very small samples. The second problem is of a similar nature: there may be random noise in determinants of the outcome variables, causing a measurement error in the treatment effect. These problems are reduced somewhat by considering only countries which have exhibited similar trends in the past in terms of life expectancy, death and birth rate and some of their key determinants. To the extent that these unobservable differences lead to a misrepresentation of the true effect, it will most likely be of an attenuating nature. Moreover, we will address this issue by performing a placebo analysis as also suggested in Abadie and Gardeazabal (2003). Thus, we will estimate synthetic control groups for all countries in our donor pool and compare deviations after treatment in the countries which were affected by HIV to deviations in the non-treated countries. This will reveal whether the treated countries are statistical outliers in terms of the estimated treatment effectin which case we would be more confident in attributing the estimated effect to the pandemic.

For our analysis, it is useful to establish two general thresholds for the prevalence of HIV. Thus, from now on, we will refer to a country as strongly affected if the estimated prevalence rate is above $1 \% .^{2}$ Likewise, we refer to countries ever experiencing prevalence rates above $10 \%$ as severely affected. The rest of the countries, i.e. those that have never crossed the $1 \%$ threshold, will be referred to as mildly affected. This categorization of countries may seem arbitrary, but it allows us to go from a continuous treatment to a discrete one.

\subsection{Selection of cases}

Some summary statistics from Oster (2012) are provided in Table 1. In the first column, we provide the estimated HIV prevalence rate as of 2007. The next column shows when a country first crossed the threshold of $1 \%$ prevalence. Clearly, all countries in the sample except Niger have done so to date, but the year of crossing varies from 1982 (Uganda) to 2007 (Senegal). Most countries entered the strongly affected group in the late 80 s or the early 90 s.

The last column in Table 1 reports the year when the countries are estimated to have crossed the $10 \%$ threshold to become severely affected (if ever). Twelve countries in the sample have done so, and the estimated timing varies between 1987 and 2001. Interestingly, some Eastern African countries (Kenya, Rwanda, Uganda), in which prevalence rates above $10 \%$ were observed, experienced a decrease in rates to a lower level in subsequent years.

Within this group of severely affected countries, we selected our cases based on three different types of considerations. The first and most important issue is data quality. Demographic information from Sub-Saharan Africa is notoriously unreliable, if available at all. This problem becomes exacerbated in our case, since we need

\footnotetext{
${ }^{2}$ Bell et al. (2006) consider a similar threshold to determine the start of the pandemic.
} 
Table 1 HIV prevalence rates

\begin{tabular}{|c|c|c|c|c|}
\hline 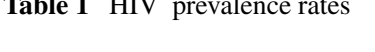 & Country & Rate & Started & Reached 10+ \\
\hline & Angola & 2.1 & 1997 & . \\
\hline & Benin & 1.2 & 1996 & . \\
\hline & Botswana & 23.9 & 1987 & 1993 \\
\hline & Burkina Faso & 1.6 & 1987 & . \\
\hline & Burundi & 2 & 1985 & . \\
\hline & Cameroon & 5.1 & 1988 & . \\
\hline & Central African & 6.3 & 1986 & . \\
\hline & Chad & 3.5 & 1988 & . \\
\hline & Congo & 3.5 & 1985 & . \\
\hline & Cote d'Ivoire & 3.9 & 1987 & . \\
\hline & Equatorial Guine & 3.4 & 1990 & . \\
\hline & Eritrea & 1.3 & 1996 & . \\
\hline & Ethiopia & 2.1 & 1991 & . \\
\hline & Gabon & 5.9 & 1991 & . \\
\hline & Ghana & 1.9 & 1994 & . \\
\hline & Guinea & 1.6 & 1999 & . \\
\hline & Guinea-Bissau & 1.8 & 1996 & . \\
\hline & Kenya & 7.8 & 1987 & 1996 \\
\hline & Lesotho & 23.2 & 1991 & 1995 \\
\hline & Liberia & 1.7 & 1993 & . \\
\hline & Malawi & 11.9 & 1988 & 1994 \\
\hline & Mali & 1.5 & 1997 & . \\
\hline & Mozambique & 12.5 & 1990 & 2001 \\
\hline & Namibia & 15.3 & 1990 & 1997 \\
\hline & Niger & .8 & . & . \\
\hline & Nigeria & 3.1 & 1991 & . \\
\hline & Rwanda & 2.8 & 1983 & 1988 \\
\hline & Senegal & 1 & 2007 & . \\
\hline & Sierra Leone & 1.7 & 1995 & . \\
\hline & South Africa & 18.1 & 1991 & 1997 \\
\hline & Swaziland & 26.1 & 1991 & 1995 \\
\hline & Togo & 3.3 & 1991 & . \\
\hline The table shows HIV & Uganda & 5.4 & 1982 & 1987 \\
\hline prevalence rates of different & United Republic & 6.2 & 1985 & . \\
\hline African countries & Zambia & 15.2 & 1984 & 1991 \\
\hline $\begin{array}{l}\text { Source: Own calculation based } \\
\text { on Oster (2012) }\end{array}$ & Zimbabwe & 15.3 & 1985 & 1990 \\
\hline
\end{tabular}

The table shows HIV prevalence rates of different African countries

Source: Own calculation based on Oster (2012)

a large number of pre-treatment years for identification. Most African countries lack a national system for vital statistics, and thus census data are a crucial source of information about changes in the population. Censuses were in some cases conducted in 
colonial times, but these are perceived to be of questionable quality (Frankema and Jerven 2014). After independence, only few countries conducted comprehensive censuses within the next decade (Zuberi and Bangha 2006). These post-colonial censuses were in general more common and of higher quality in Anglophone countries than elsewhere. However, the information from these early post-colonial censuses has also been lost in many cases (Zuberi and Bangha 2006).

The United Nations population estimates for the early post-colonial period are believed to be the most reliable source (Manning 2010). They are typically based on late colonial censuses as well as censuses from the early years of independence (Frankema and Jerven 2014). There have been several revisions since the first estimates, but the UN figures and those from the World Development Indicators have been harmonized. In general, our knowledge of African populations improved considerably during the second half of the twentieth century, partly due to a marked progress in the quality of data collection. However, UN population estimates still deviate strongly in some cases, in particular for early post-independence years, from alternative sources such as the Penn World Tables (Frankema and Jerven 2014).

We used two distinct criteria for data quality: firstly, that the country had a comprehensive census no later than 1965, and, secondly, that the discrepancy between UN and PWT estimates of the 1960 population is less than $10 \%$. These criteria identified Botswana, Namibia, South Africa and Zimbabwe. For Mozambique, no information on censuses is available, but since the country satisfies the discrepancy criterion, we decided to include it anyway.

Our second criterion is size. It is clearly of greater interest to study countries with larger populations. We thus decided to exclude countries with less than 1 Million inhabitants in 1960 - which applies to Botswana and Namibia.

Finally, we required that the countries perform well in terms of their pre-treatment fit with the synthetic control group. This restriction was, however, not binding, since all three countries that had survived the previous stages turned out to have an excellent pre-treatment fit for all the three outcome variables.

\subsection{Control group}

We defined our control group as countries which, according to UNAIDS estimates, have never crossed the $1 \%$ prevalence threshold-i.e. the group of mildly affected countries according to the categorisation above. As Table 2 reveals, there is a large number of countries available which are at different levels of development. In a first set of estimates, we based the analysis on African countries from this group, and applied our data quality criterion, which resulted in a donor pool of ten countries. As a sensitivity check and in order to conduct inference based on placebo estimates, we relaxed these criteria in a second step, and based the analysis on the entire set of donors.

There are 40 additional countries for which HIV prevalence statistics are available, but since these belong to the strongly but not severely affected countries, we could not use them in our main analysis. The vast majority of these countries are African, but notable exceptions are Ukraine, Jamaica and Thailand. 
Table 2 Control group: mildly affected countries

\begin{tabular}{|c|c|c|c|}
\hline Country & Prev 2007 & Country & Prev 2007 \\
\hline Algeria & .1 & Argentina & .4 \\
\hline Armenia & .1 & Australia & .1 \\
\hline Austria & .3 & Azerbaijan & .1 \\
\hline Bangladesh & .1 & Belarus & .2 \\
\hline Belgium & .2 & Bhutan & .1 \\
\hline Bolivia & .2 & Bulgaria & .1 \\
\hline Cambodia & .6 & Canada & .2 \\
\hline Chile & .4 & Colombia & .6 \\
\hline Comoros & .1 & Costa Rica & .3 \\
\hline Croatia & .1 & Cuba & .1 \\
\hline Czech Republic & .1 & Denmark & .2 \\
\hline Dominican Republic & .8 & Ecuador & .4 \\
\hline Egypt & .1 & El Salvador & .8 \\
\hline Fiji & .1 & Finland & .1 \\
\hline France & .4 & Georgia & .1 \\
\hline Germany & .1 & Greece & .1 \\
\hline Guatemala & .7 & Hungary & .1 \\
\hline Iceland & .3 & India & .4 \\
\hline Indonesia & .1 & Iran & .2 \\
\hline Ireland & .2 & Israel & .2 \\
\hline Italy & .3 & Japan & .1 \\
\hline Kazakhstan & .1 & Korea Rep & .1 \\
\hline Kyrgyzstan & .2 & Lao PDR & .2 \\
\hline Latvia & .6 & Lebanon & .1 \\
\hline Lithuania & .1 & Luxembourg & .3 \\
\hline Madagascar & .2 & Malaysia & .5 \\
\hline Maldives & .1 & Malta & .1 \\
\hline Mauritania & .7 & Mexico & .3 \\
\hline Qatar & .1 & Moldova & .4 \\
\hline Mongolia & .1 & Morocco & .1 \\
\hline Myanmar & .6 & Nepal & .4 \\
\hline Netherlands & .2 & New Zealand & .1 \\
\hline Nicaragua & .2 & Norway & .1 \\
\hline Oman & .1 & Pakistan & .1 \\
\hline Papua New & .9 & Paraguay & .3 \\
\hline \multicolumn{4}{|l|}{ Guinea } \\
\hline Peru & .4 & Philippines & .1 \\
\hline Poland & .1 & Portugal & .5 \\
\hline Romania & .1 & Senegal & .8 \\
\hline Serbia & .1 & Singapore & .1 \\
\hline Slovakia & .1 & Slovenia & .1 \\
\hline
\end{tabular}


Table 2 (continued)

The table shows HIV prevalence rates of the control group

Source: Own calculations based on UNAIDS data

\begin{tabular}{llll}
\hline Country & Prev 2007 & Country & Prev 2007 \\
\hline Somalia & .6 & Spain & .4 \\
Sri Lanka & .1 & Sweden & .1 \\
Switzerland & .4 & Tajikistan & .2 \\
Tunisia & .1 & Turkey & .1 \\
United Kingdom & .2 & United States & .6 \\
Uruguay & .5 & Uzbekistan & .1 \\
Vietnam & .4 & &
\end{tabular}

\subsection{Assumptions}

We now present the main assumptions needed for the analysis. Since the HIV epidemic reached critical levels in different countries at different points in time, each affected country needs to be analysed separately. Thus, in the notation below, we proceed as if there were only one single treated unit and $J$ further control units.

We denote by $Y_{i t}^{N I}$ the outcome that would have been observed in country $i$ at time $t$ in absence of the HIV epidemic. Also, we denote by $T_{0}$ the last pre-intervention period, i.e.

$$
T_{0}=\inf \left\{t \mid R_{1 t} \geq 0.01\right\}-1,
$$

where $R_{1 t}$ denotes the HIV prevalence rate in the affected country.

Moreover, let $Y_{i t}^{I}$ be the outcome for the affected country $i$ at time $t$, where the epidemic had started to take off at time $T_{0}+1$. Since HIV is unlikely to have had an effect on the outcome variables before the outbreak of the pandemic, we also have $Y_{i t}^{I}=Y_{i t}^{N I} \forall t=1, \ldots, T_{0}, \forall i=1, \ldots, J+1$.

Next, define $A_{i t} \equiv Y_{i t}^{I}-Y_{i t}^{N I}$ as the effect of the HIV epidemic for unit $i$ at time $t$, and let $D_{i t}$ be an indicator which assumes the value one whenever the HIV epidemic has crossed the $1 \%$ threshold: $D_{1 t}=\mathbf{1}\left(t>T_{0}\right)$. Thus, the observed outcome for unit $i$ at time $t$ equals

$$
Y_{i t}=Y_{i t}^{N I}+A_{i t} D_{i t}
$$

Abadie et al. (2010) suggest that the untreated value $Y_{i t}^{N I}$ can be described by a factor model given by the following equation:

$$
Y_{i t}^{N I}=\delta_{t}+\theta_{t} Z_{i}+\lambda_{t} \mu_{i}+\epsilon_{i t}
$$

where $\delta_{t}$ is a time effect common to all units, $\theta_{t}$ is a vector of possibly time-dependent coefficients, $\lambda_{t}$ is a vector of unobserved common factors and $\mu_{i}$ is a vector of unknown factor loadings.

The method allows for some degree of endogeneity in the treatment indicator-in the sense that the occurrence of the intervention may be correlated with unobservables. Nevertheless, it seems not completely unreasonable to assume that, in the early stages, the spread of the disease was relatively exogenous and mainly driven by geographical factors (all countries in the Sub-Saharan region were hit by the disease), 
while the actual prevalence level reached in each country will also be influenced by other factors, such as poverty. Moreover, available evidence suggests that the pandemic spread at a very high speed during the early years in affected countries. For example, in Malawi, the first AIDS case was diagnosed in 1985, a $1 \%$ prevalence rate was reached in 1988, and in 1990 the prevalence rate was already at $2 \%$ (Arrehag et al. 2006). Our data show that the average time it took from a prevalence rate of $0.5 \%$ until reaching $1 \%$ was 1.1 years, while only 14 out of 91 mildly affected countries ever reached a prevalence rate greater or equal to $0.5 \%$.

A rapid onset of the epidemic is desirable for modelling purposes since the postulated "start year" then becomes less arbitrary. Besides, the incubation period is some 6-8 years on average, which means that governments and aid agencies had very limited possibilities of moderating the epidemic during the early years (Gaffeo 2003). Thus, treatment assignment is reasonably exogenous, whereas the development and wider spread of the disease is probably not. A further assumption which is needed for the method to work is that the outcomes of non-treated countries are unaffected by the intervention. There are several ways in which this assumption could be violated. For example, there is obviously the risk of contagion, to the extent that the countries of the control group also become affected by the pandemic. Oster (2012) delivers strong evidence that trade between countries elevates incidence rates. However, this possibility has been eliminated by considering only countries which have had very low prevalence rates throughout.

It is also desirable that there is no other extraordinary shock affecting the outcome variables after time period $T_{0}$-for the treated country or for the donor countries. These shocks could be events like hunger crises, natural disasters, or wars. It could of course be argued that the method controls for such shocks, since the comparison units - the synthetic control groups-have been defined so as to closely mimic the behaviour of all relevant variables in the treated country, including severe and unexpected exogenous shocks. However, inference from the method is based on small samples, and, for this reason, the occurrence of an exogenous large-scale shock can lead to erroneous conclusions.

As mentioned in Section 2, a further complication in our analysis is the possibility of migration in response to the pandemic. Such selective migration represents one out of many effects the pandemic might have on demographic outcomes. Since we conduct a reduced-form analysis, which incorporates all different behavioural responses into one estimated treatment effect, it is unlikely that migration leads to a bias in the estimates. However, it is nevertheless a good thing that the migration flows to and from the affected countries have been relatively modest, since otherwise it would be much more difficult to interpret results.

\subsection{Implementation}

The synthetic control method involves estimating two matrices: $\mathbf{V}$ is the weighting matrix determining the relative predictive power of various outcome variables $Z_{i}$ and of the outcome variable itself. The vector $\mathbf{W}$ is a vector of non-negative weights given to the $J$ control countries. 
The criterion minimised is given by

$$
\left\|\overline{\mathbf{X}}_{1}-\overline{\mathbf{X}}_{0} \mathbf{W}\right\|_{\mathbf{V}}=\sqrt{\left(\overline{\mathbf{X}}_{1}-\overline{\mathbf{X}}_{0} \mathbf{W}\right)^{\prime} \mathbf{V}\left(\overline{\mathbf{X}}_{1}-\overline{\mathbf{X}}_{0} \mathbf{W}\right)},
$$

where $\overline{\mathbf{X}}_{j}$ is a vector of averages over the pre-treatment period of elements of $Z_{i}$ and $Y_{i}$, for treated and control units, respectively. This will give us an optimal country weight matrix amongst all diagonal positive definite matrices depending on the variable weight $\left(W^{*}(V)\right)$.

The predictors $\mathrm{V}$ are chosen such that the average distance from the outcome variable, i.e. the root of the mean squared prediction error is minimized in pre-intervention periods:

$$
R M S P E=\sqrt{\frac{\sum_{t}\left(Y_{1, t}-\mathbf{Y}_{\mathbf{0}, \mathbf{t}} \mathbf{W}^{*}(\mathbf{V})\right)^{2}}{N}},
$$

where $N$ represents the number of years in the pre-treatment period.

\subsection{Treatment effects and inference}

In addition to the above-mentioned RMSPE in the pre-treatment period, we will calculate the RMSPE in the post-treatment period as suggested by Abadie et al. (2010). Moreover, we are interested also in the direction of the effect. Therefore, we calculate the mean prediction error (MPE), based on the following formula:

$$
M P E=\frac{\sum_{t}\left(Y_{1, t}-\mathbf{Y}_{\mathbf{0 , t}} \mathbf{W}^{*}(\mathbf{V})\right)}{N} .
$$

Theoretically, the estimated effect for a country could change sign with the passage of time, and in the $M P E$ measures, positive and negative effects would then cancel out and thus attenuate the results. Nevertheless, the measure represents a useful summary statistic in terms of the sign and cumulative size of the effect.

Abadie et al. (2010) suggested different ways of using placebo regressions for conducting inference based on the mean square prediction error. If units with an acceptable pre-treatment fit are compared, their ranking after the "treatment" would be completely random under the null hypothesis of no treatment effect. Inference can then be drawn based on the probability that the treated unit would have attained a position equal to or higher in the RMSPE or MPE rankings, if these rankings had been randomly assigned.

We use the same approach in this paper. However, since we include several treated units, we also adjust our inference method for multiple testing-using an approach similar in spirit to the Mann-Whitney $U$ test (Siegel 1956). ${ }^{3}$ Thus, if we denote the ranks of the three countries by $\left(r_{1}, r_{2}, r_{3}\right)$, where $r_{1}<r_{2}<r_{3}$, we base inference on the probability that a random draw would have generated (ordered) ranks

\footnotetext{
${ }^{3}$ A multiple testing problem also arises due to the inclusion of three distinct outcome variables. We ignore this problem here, but it will become clear that it does not affect our conclusions.
} 
$\left(\rho_{1}, \rho_{2}, \rho_{3}\right) \leq\left(r_{1}, r_{2}, r_{3}\right)$, where the inequality is componentwise. Thus, for significance level $\alpha$, we would require $\operatorname{Pr}\left[\left(\rho_{1}, \rho_{2}, \rho_{3}\right) \leq\left(r_{1}, r_{2}, r_{3}\right)\right] \leq \alpha$ in order to conclude that the results are significant.

Also, in general, it is possible to calculate a $p$ value for the three draws $\left(r_{1}, r_{2}, r_{3}\right)$, representing the exact probability that three randomly drawn ranks $\left(\rho_{1}, \rho_{2}, \rho_{3}\right)$ are componentwise lower than or equal to the observed ranks $\left(r_{1}, r_{2}, r_{3}\right)$. For a total of $N$ treated and donor countries, the $p$ value becomes

$$
p=\frac{r_{1}\left(3 r_{2}\left(2 r_{3}-r_{2}-1\right)-3 r_{3}\left(1+r_{1}\right)+2+3 r_{1}+r_{1}^{2}\right)}{N \cdot(N-1) \cdot(N-2)}
$$

For example, if there are 94 countries in total and the 3 treated countries attain ranks $(1,2,3)$, the associated $p$ value is 0.00000746 ; if the ranks are $(92,93,94)$, the $p$ value equals one, whereas an intermediate result of $(33,58,86)$ is associated with $p$ value 0.5 . Finally, the ranks $(20,21,46)$ lead to a statistically significant result with a $p$ value equal to 0.049 . This test can be either one-sided or two-sided depending on the metric used (RMSPE does not discriminate according to effect sign, whereas MPE does) and on the null hypothesis.

\section{Data and variables}

As previously mentioned, Sub-Saharan Africa is the region with by far the largest number HIV/AIDS infected and the highest prevalence rates. But even this region exhibits regional heterogeneity in prevalence rates and different time frames in the development of the disease. Moreover, evidence suggests that the pandemic spread very rapidly during the early years in affected countries. However, there is a general problem of quantifying the real HIV/AIDS prevalence rate in these countries due to data limitations. Given that the real figures of HIV/AIDS prevalence rates can no longer be measured for the past, reasonable assumptions need to be made. The data provided by Oster (2012) are based on UNAIDS statistics and trend information as well as linear interpolation. The UNAIDS data themselves are derived from several different sources, such as population-based tests, prenatal clinical data, countrywide HIV organization data and epidemic modelling. These data appear to be the best available and as there are no huge discrepancies in the HIV/AIDS prevalence data, there will also be no significant discrepancies in the result of the estimates based on different sources (as long as no systematic error in deriving the prevalence data was made).

The other variables used here were taken from different sources and come with the same problems as the HIV/AIDS prevalence rates. Data for birth rates and death rates were obtained from the World Bank datasets (The World Bank 2011), and data on life expectancy were collected from different sources and compiled by Rosling (2014). Our dependent variables are crude death and birth rates (per 1,000 inhabitants) and average life expectancy (at birth). We use death rates instead of adjusted mortality because this measure provides the largest dataset in terms of countries we are able to consider. A consequence of this choice is that it is desirable to also condition on variables which capture the age distribution. 
As Section 3.3 reveals, the choice of variables included in $\mathbf{X}$ will influence the countries the estimator uses to replicate the treated country and will thus also determine the outcome of the estimation. We employ values of the dependent variable at three different points in time starting with the initial value $Y_{i 0}$, up to the year before treatment. Moreover, we include important determinants of mortality such as the percentage of smokers (obtained from $\mathrm{Ng}$ et al. 2014), under-5 mortality (Rajaratnam et al. 2010) and cancer data (Forouzanfar et al. 2011) for the dependent variables life expectancy and death rate. Conditioning on under-5 mortality not only captures the disease environment, but also helps adjusting for the age distribution amongst the diseased. Controlling for smoking behaviour and cancer rates is particularly useful when comparing countries at different levels of development - since the death causes related to these factors vary strongly with living standards. Finally, we include the total fertility rate and the mean age at childbearing as covariates for the analysis of birth rates (Nations United 2013).

Combining all these variables from various datasets, we are able to construct a balanced panel of 94 countries ( 3 treated and 91 in the donor pool, 10 of which are African countries) from 1960 to 2008. The intervention years for the three treated countries, i.e. the year in which they crossed the $1 \%$ hurdle of HIV prevalence, are as follows: 1990 for Mozambique, 1991 for South Africa and 1985 for Zimbabwe 1985 (cf. Table 1) — which gives us around 30 pre-intervention years and 19 postintervention years.

The synthetic control group estimator uses the average of several control countries in order to replicate a treated country. However, the heterogeneity between these donors is not taken into account. For example, a country with a life expectancy of 50 years could be replicated by another country with a life expectancy of 50 yearsor by two countries with a life expectancy of 30 and 70 years, respectively. The results might depend upon whether rather similar or rather different countries are chosen by the estimator. Abadie et al. (2010) recommends using rather similar donors. Thus, we first conduct the analysis based on African donors with high-quality demographic information only. In order to check robustness of our findings and to conduct inference, we use the entire donor pool in a separate set of specifications.

Analysing the treated countries and their donor pools, we construct control countries. We build a synthetic control unit for each treated country by weighting the donors so as to resemble each treated country as closely as possible in the time interval before the treatment. In the next section, we present the results of this optimization.

\section{Results}

\subsection{African donors}

\subsubsection{Performance}

In Table 3, we present donor weights for the different specifications, and in Table 4, we present results for covariate balance with this very limited donor pool. We also 


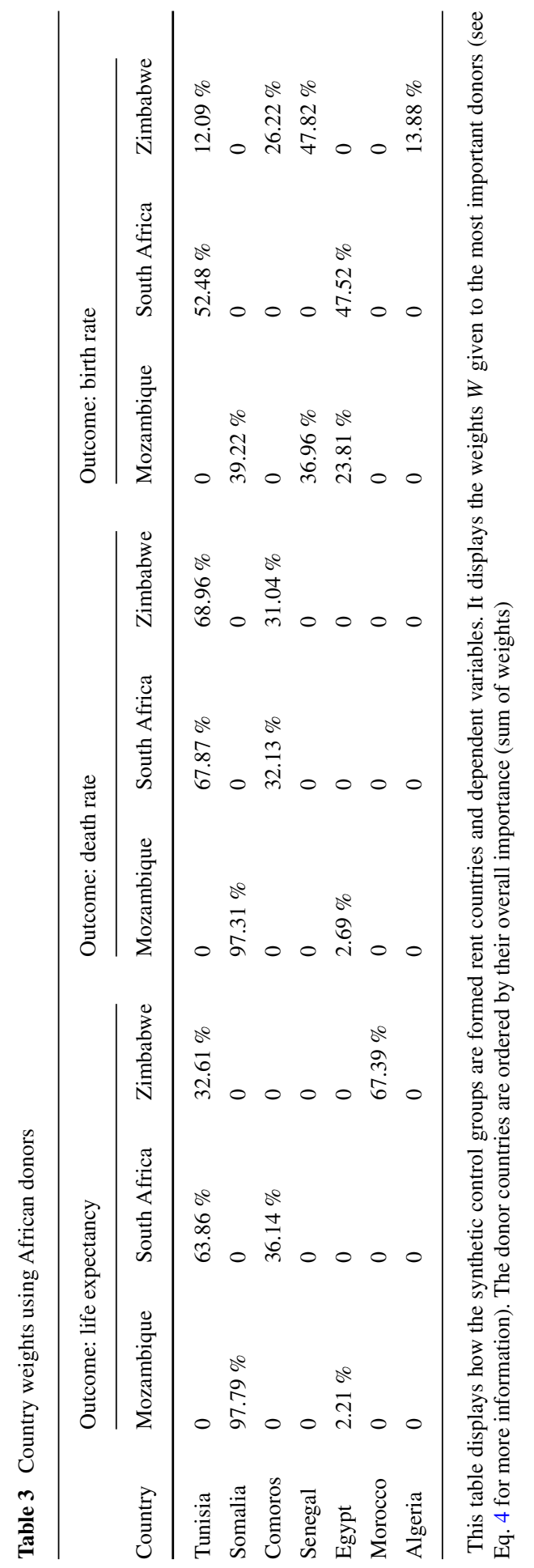




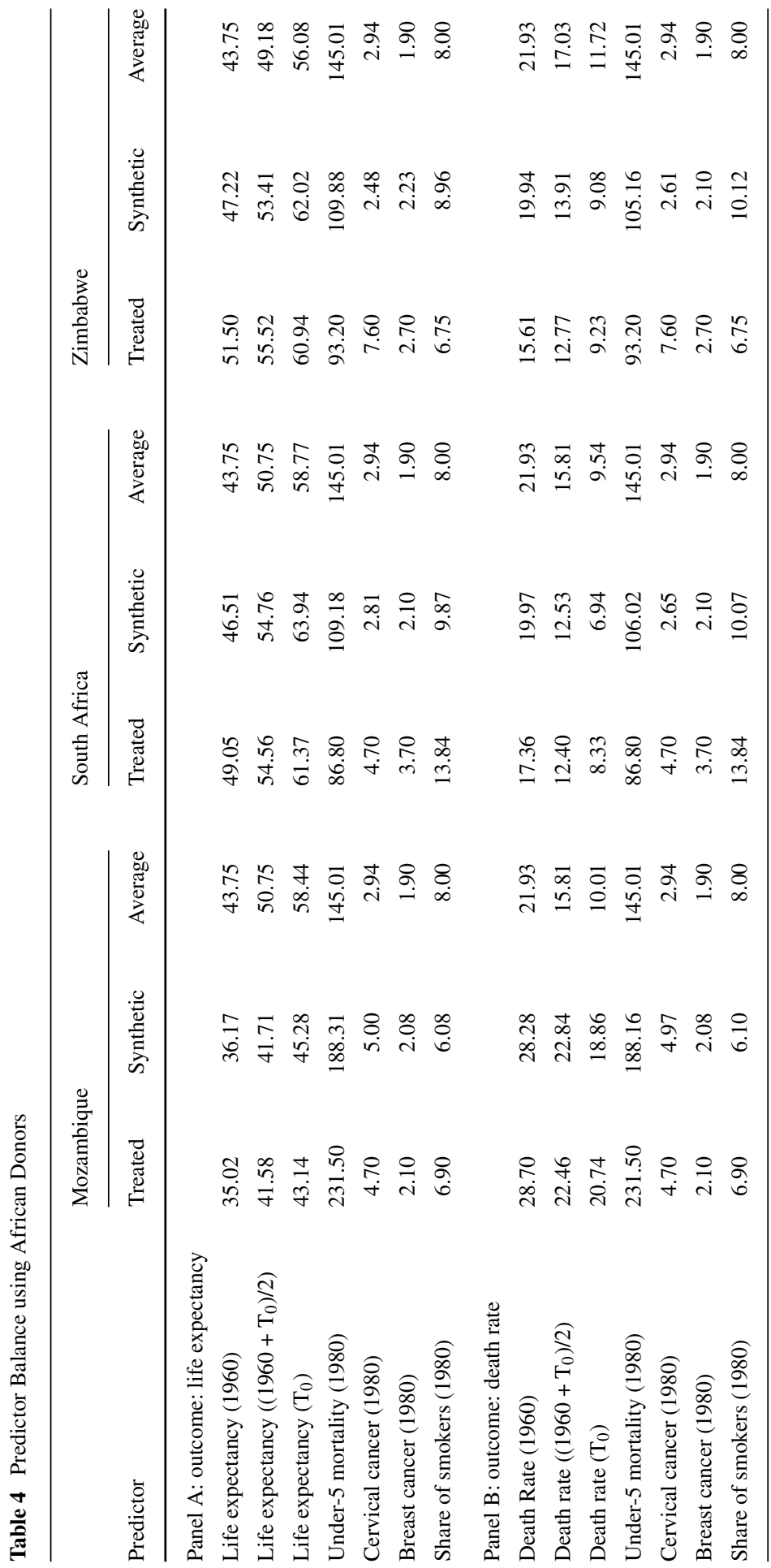




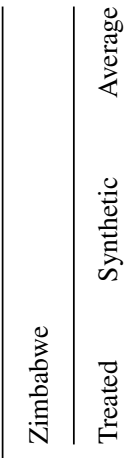

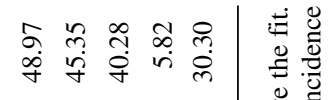

范

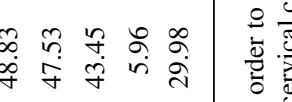

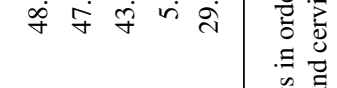

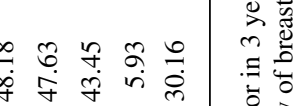

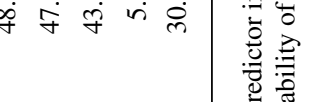

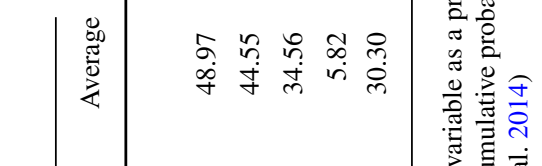

चี

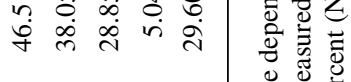

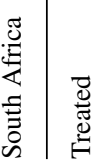

Е

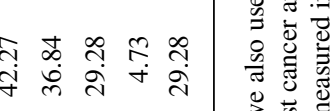

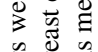

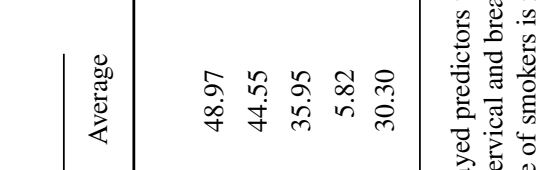

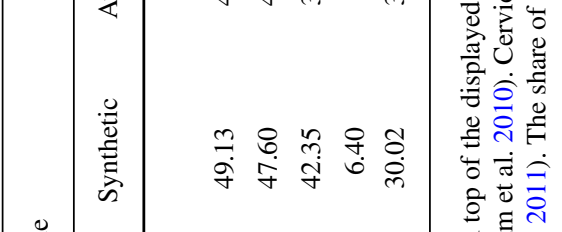

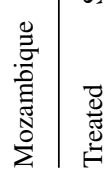

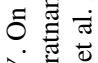

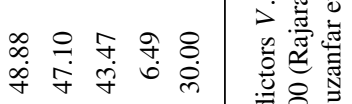

苟

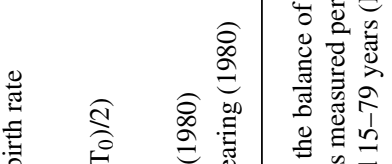

ฮี

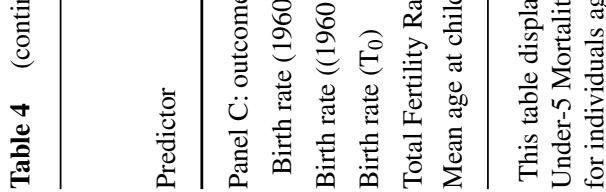


report results for the balancing of the outcome variable; however, this aspect will be discussed in more detail when we present estimation results below. For comparison, we also present the averages for outcomes and covariates within the entire donor pool.

For the outcomes life expectancy and death rate, four indicators from 1980 are identified as important predictors beside the outcome variable itself: the under-5 mortality rate, the prevalence of two types of cancer, and the share of smokers in the population. For the outcome birth rate, two predictors qualify: the TFR, and the mean age at childbearing.

It is clear from Table 4 that despite the low number of donors available, the algorithm produces a much better match than a simple average taken across all donors. For Mozambique, the balance is improved for all ten covariates when using the synthetic control instead of all donors. In some cases-TFR and prevalence of breast cancerthe match is almost perfect with a deviation of less than $2 \%$, whereas in other cases it is less satisfactory. The largest mismatch is observed for the under-5 mortality rate in 1980, but also for this variable, the improvement in covariate balance is considerable. For South Africa, we observe an improvement for eight out of ten indicators, and for Zimbabwe only five out of ten are better matched to the synthetic control group.

The most striking discrepancies are observed for the cancer-related variables and for the share of smokers. Whereas Mozambique performs very well also on those variables, there are worrying differences for the other two countries. In general, the cancer death rates are underestimated: the real South Africa is reported to have a cervical cancer death rate of 4.7 per 100,000, and synthetic South Africa only 2.81 . The corresponding figures for Zimbabwe are 7.6 and 2.48, respectively. In both cases, taking a crude average of donors would have been slightly better (average: 2.94) for this indicator. Breast cancer death rates are also underestimated for these two countries.

The main reason for the mismatch is that our three countries tend to have relatively high death rates for cervical cancer but low death rates for breast cancer, which makes it difficult to find suitable matches in this very restrictive group of donors. The impact of this mismatch is, however, likely to be relatively small, for the following reason: the total death toll attributable to these two cancers varies between 8 and 15 cases per 100,000 population for these 3 countries (World Health Organization 2004). The all-cause death rate ranges between 800 and 2000 at the beginning of the treatment period. Since we attain a very good match for the overall death rates, the main consequence of the mismatch on cancers is that the synthetic control groups will have marginally lower death rates for cancers and marginally higher death rates for other death causes. Since these two cancers disproportionately affect women aged 50 and over (Forouzanfar et al. 2011), a possible consequence might be that the impact of HIV on death rates is slightly underestimated-since the chances are greater that HIV replaces deaths which would have happened "anyway". However, since we also observe an excellent match on life expectancy, the age-specific mortality rates cannot be very different, which in turn suggests that this possible bias should be of limited importance.

Another concern is the poor covariate balance for smoking rates-again for South Africa and Zimbabwe. The synthetic control underestimates smoking prevalence by around one-third for South Africa, and overestimates it by the same fraction for 
Zimbabwe. For Mozambique, on the other hand, the match is acceptable. The three main death causes associated with smoking - cardiovascular disease, lung cancer and chronic obstructive lung disease - are responsible for between 7 and $15 \%$ of total deaths in the three countries: the highest proportion is reported for South Africa (World Health Organization 2004). Hence, a mismatch in smoking prevalence of a few percentage points between treated and synthetic control could possibly lead to a bias in the estimated effect, but similar caveats apply as for the cancers mentioned above. However, we are unable to adjust for smoking intensity, which possibly leads to a misrepresentation of the true impact of smoking prevalence. We will return to this issue when we discuss covariance balance in the larger donor pool in Section 5.2.

There is some heterogeneity in terms of countries employed as donors (Table 3). The most important countries in terms of weights are Tunisia and Somalia. While Tunisia is an important donor for South Africa (45-68\% depending on the dependent variable) and Zimbabwe (0-69\%), Somalia is the dominant donor for Mozambique (32-98\%). This high weight assigned to Somalia in the case of Mozambique could be a reason for concern. However, when we allow more donors below, the weight of Somalia drops considerably (the weight is between 1.5 and $41 \%$ in Table 6) without affecting the results.

In conclusion, we see that the algorithm produces a significant improvement in covariate balance overall, but there are still some striking discrepancies which we will try to address in what follows, using a larger donor pool. In terms of the quality of the match, results are particularly promising for Mozambique, where the average covariate discrepancy is less than $10 \%$ for all the three outcome variables considered. Likewise, the degree of covariance balance seems to be particularly high when the birth rate is used as an outcome: for this outcome, the average discrepancy is less than $5 \%$ for all three countries. These two points should be kept in mind when interpreting the results below.

\subsubsection{Results}

In Table 5, we then present our main results for this restricted sample. For each of the three outcome variables, the panels report the RMSPE before treatment, the corresponding variable after treatment, the mean prediction error and the prediction error in 2008. Clearly, Mozambique exhibits the best overall performance with respect to the pre-treatment match of the three outcome variables. For birth rates, the prediction error is as small as $2.07 \%$, and for none of the outcomes, it is greater than $7 \%$. This is relatively low in comparison with many other studies using the same method, ${ }^{4}$ and slightly surprising considering the small number of donors available. South Africa and Zimbabwe exhibit a slightly worse pre-treatment fit, but results are still clearly acceptable.

As regards the estimated effect, we find mixed results across outcomes and countries. Not surprisingly, the HIV pandemic is associated with a large reduction in life

\footnotetext{
${ }^{4}$ Abadie et al. (2010) obtain a value of around 2.8-5.1\% in their analysis, while Hinrichs (2012) and Montalvo (2011) report even larger discrepancies.
} 
Table 5 Results for African donors

\begin{tabular}{|c|c|c|c|c|c|c|c|c|}
\hline & \multicolumn{2}{|l|}{ RMSPE } & \multicolumn{2}{|c|}{ RMSPE post } & \multicolumn{2}{|l|}{ MPE } & \multicolumn{2}{|l|}{ PE 2008} \\
\hline \multicolumn{9}{|c|}{ Panel A: life expectancy } \\
\hline & In logs & In years & In logs & In years & In logs & In years & In logs & In years \\
\hline Mozambique & $3.43 \%$ & 1.46 & $3.05 \%$ & 1.47 & $-1.94 \%$ & -0.94 & $-4.67 \%$ & -2.29 \\
\hline South Africa & $3.20 \%$ & 1.71 & $21.27 \%$ & 12.99 & $-19.06 \%$ & -11.71 & $-31.63 \%$ & -19.18 \\
\hline Zimbabwe & $4.95 \%$ & 2.55 & $36.17 \%$ & 20.31 & $-30.16 \%$ & -17.16 & $-48.38 \%$ & -27.68 \\
\hline \multicolumn{9}{|c|}{ Panel B: death rate } \\
\hline & In logs & In deaths & In logs & In deaths & In logs & In deaths & In logs & In deaths \\
\hline Mozambique & $6.13 \%$ & 1.23 & $4.14 \%$ & 0.71 & $2.72 \%$ & 0.45 & $4.11 \%$ & 0.64 \\
\hline South Africa & $8.29 \%$ & 1.25 & $61.87 \%$ & 5.81 & $56.16 \%$ & 5.10 & $91.76 \%$ & 9.13 \\
\hline Zimbabwe & $13.82 \%$ & 2.23 & $75.35 \%$ & 8.01 & $63.49 \%$ & 6.56 & $97.04 \%$ & 9.94 \\
\hline \multicolumn{9}{|c|}{ Panel C: birth rate } \\
\hline & In logs & In births & In logs & In births & In logs & In births & In $\log s$ & In births \\
\hline Mozambique & $1.78 \%$ & 0.80 & $10.55 \%$ & 4.29 & $10.11 \%$ & 4.11 & $7.07 \%$ & 2.67 \\
\hline South Africa & $6.93 \%$ & 2.70 & $11.91 \%$ & 2.72 & $10.79 \%$ & 2.48 & $6.09 \%$ & 1.30 \\
\hline Zimbabwe & $1.32 \%$ & 0.63 & $2.00 \%$ & 0.64 & $-1.77 \%$ & -0.58 & $-2.64 \%$ & -0.80 \\
\hline
\end{tabular}

This table shows the estimated effects for each country. The root mean square prediction error (RMSPE) is defined in Eq. 5. We calculate it before the intervention (column 2), and after (column 4). Column 6 reports the MPE (mean precition error; see Eq. 6). Finally, we show the difference of the outcome variable in the final period (2008) in column 8. Results are provided in logarithmic scale and in the natural units, i.e. years of life expectancy and death and births per 1,000 inhabitants

expectancy and a corresponding increase in mortality rates - the effect is as large as $19 \%$ (11.7 years by the year 2000) for life expectancy in South Africa, and $30 \%$ (15 years) in Zimbabwe. However, we do not observe anything comparable in Mozambique: the overall effect is as low as $2 \%$ (1.4 years). Interestingly, the relative effect on death rates is larger than the effect on life expectancy, but the results for the two outcomes are very consistent with each other.

For the birth rate, results are more moderate and partly contradictory. Mozambique and South Africa note an increase in birth rates by around $10 \%$, whereas Zimbabwe experiences a reduction of about $2 \%$. This result will be corroborated below but we may already conclude that the conflicting evidence delivered in the previous literature may in fact be attributable to the effects being relatively small overall, and to heterogeneity in the impact between different countries.

In summary, this analysis based on African donors has shown a strong effect on life expectancy and death rates for Zimbabwe and South Africa, but, surprisingly, virtually no effect for Mozambique. This is particularly puzzling considering that Mozambique exhibits by far the best fit in terms of covariate balance and pretreatment prediction error. We observe a smaller and heterogeneous effect on birth rates. Finally, we find that a very good synthetic control-in terms of covariate balance and pre-treatment fit - can be built for Mozambique, whereas the two other countries, in particular Zimbabwe, perform slightly worse. 
On the other hand, there are some reasons why we feel that this analysis needs to be corroborated using a larger number of cases. Firstly, credible inference can only be conducted if the number of donors is relatively high. Secondly, it would be desirable to increase the covariate balance and to check whether results remain robust when the pre-treatment fit is improved. Thirdly, if results remain robust, it would be of interest to evaluate the power concerning our surprising finding for Mozambique that the HIV virus hardly affected life expectancy and death rates. Likewise, if the results for birth rates are robust, it would be of interest to evaluate whether the method is suitable to pick up effects in this variable at all. Thus, we now relax two of our sample selection criteria and allow non-African donors as well.

\subsection{All donors}

\subsubsection{Performance}

With a less restrictive sample selection, we have a total of 91 donors which may be used. Donor weights are provided in Table 6, and in Table 7, we present results for covariate balance, using the same indicators as in the restricted analysis above. Clearly, relaxing the restriction leads to a marked improvement in covariate balance: now the synthetic control group represents an improvement in the balance for all indicators and all countries, compared to the average of each of the two donor pools we consider. Also in comparison to the previous synthetic controls, we observe improvements. In particular, we noticed a discrepancy in terms of under-5 mortality, especially for Mozambique. This difference now decreased substantially for all three countries. For Mozambique, we previously observed that under-5 mortality was lower in the synthetic control group, while now we observe a slightly higher under5 mortality rate, while all other results are unchanged. For the total fertility rate-a covariate used to predict the birth rate-the deviation between the actual and the synthetic version of the countries ranged between 1 and $6 \%$, and now the discrepancy is down to virtually zero. Similar improvements in fit are notable for the other indicators.

Even though the overall performance is remarkably good, there are also a couple of exceptions. The largest relative deviations between treated and controls are now observed for the variable capturing smoking prevalence. There was an issue with the match for this covariate also in the previous analysis focusing on African donors. In this new estimate, the match for South Africa is acceptable, whereas Mozambique and Zimbabwe exhibit deviations ranging between 26 and $55 \%$. For Mozambique, the prevalence of smoking is underestimated, and for Zimbabwe, it is overestimated. A closer inspection of the underlying data reveals that for both countries, the treated country lies right in the middle of the donor countries in terms of smoking prevalence-some donors exhibit higher smoking rates, and some exhibit lower rates. Thus, using different weights, it would in principle have been possible to replicate the smoking prevalence rates for Mozambique and Zimbabwe, but the current weights are obviously not optimised for replicating this variable. On the other hand, there is actually some evidence suggesting that the discrepancies between treated and controls tend to exaggerate differences in smoking behaviour: according to the same 


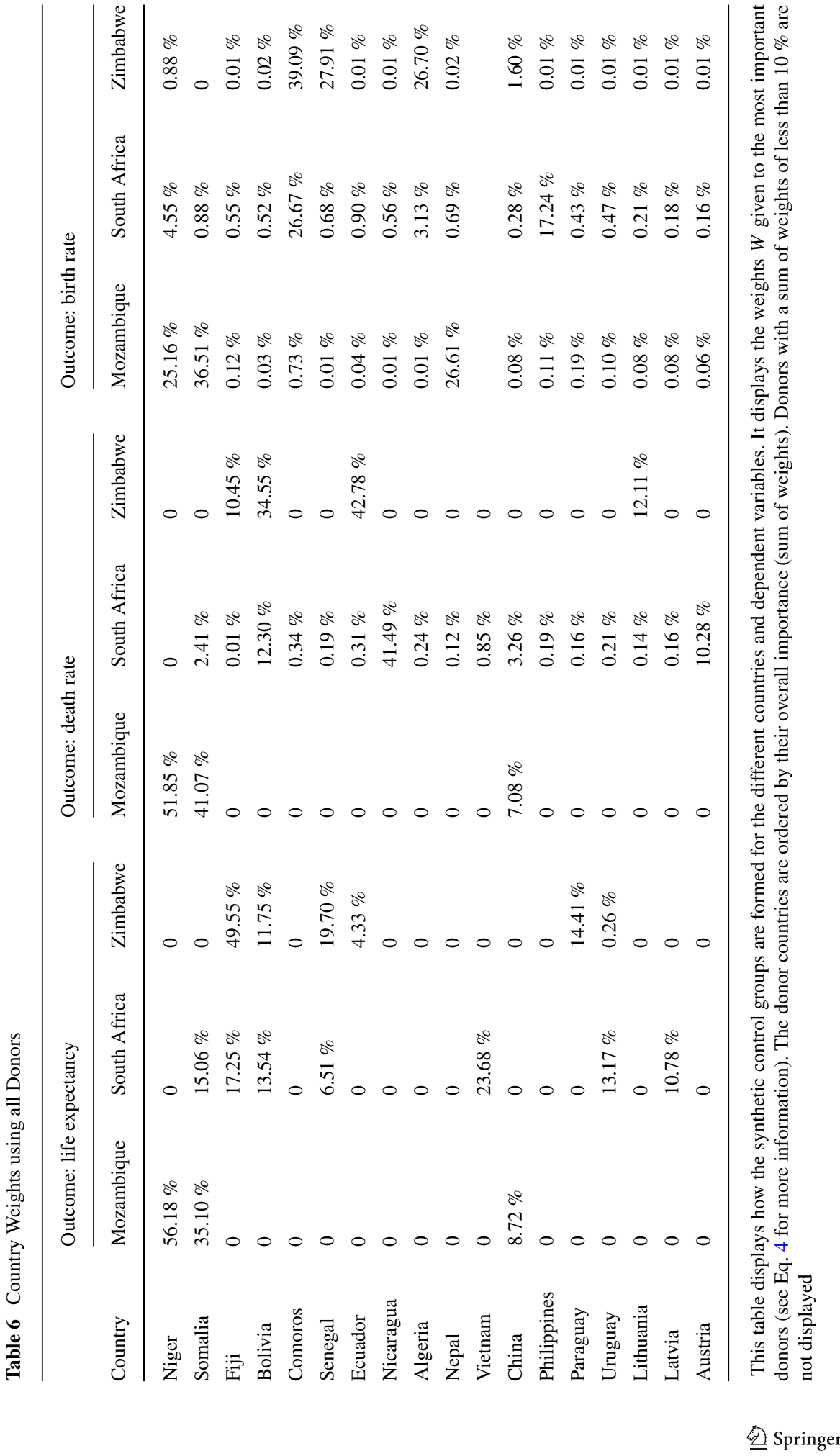




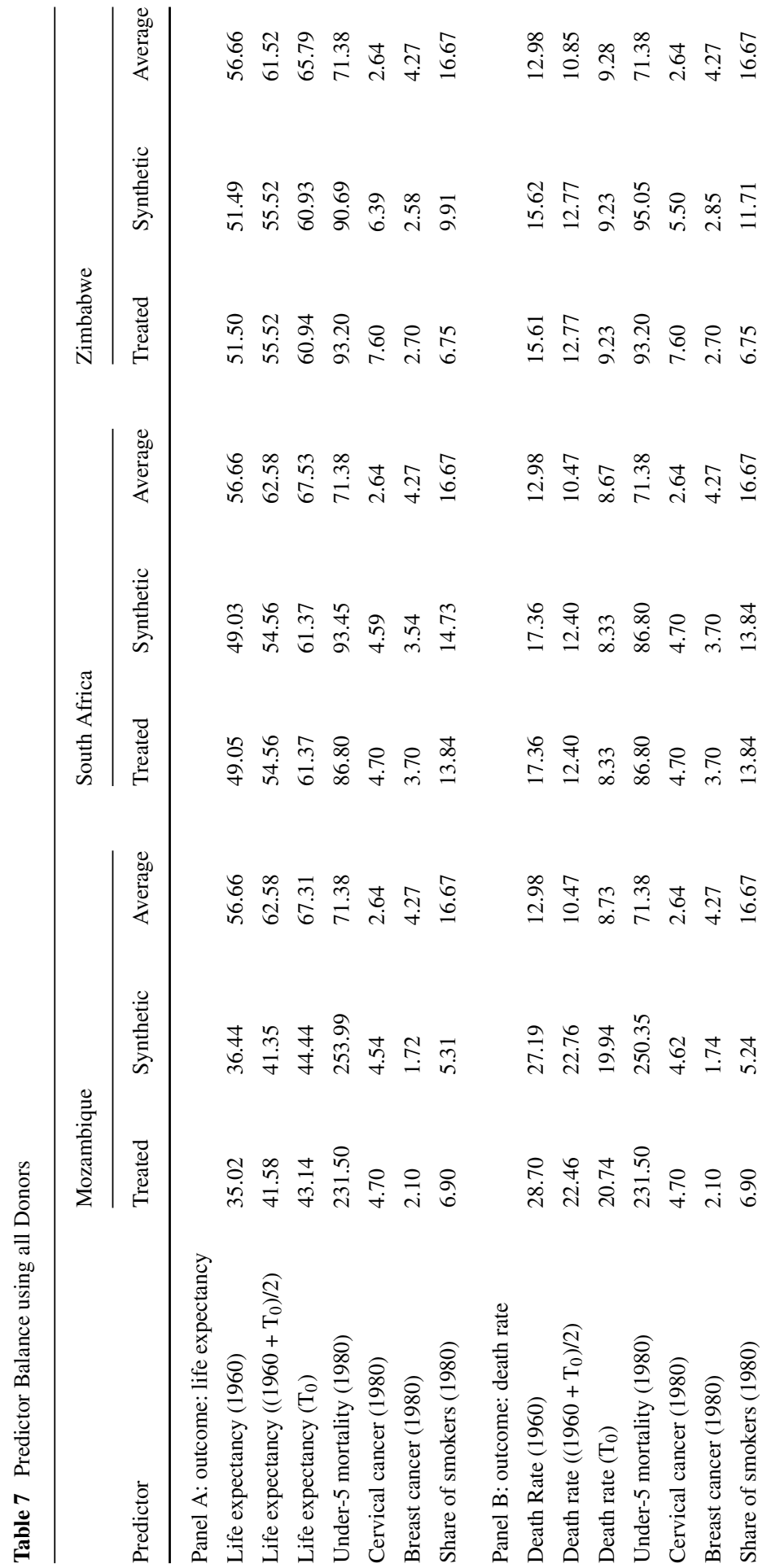




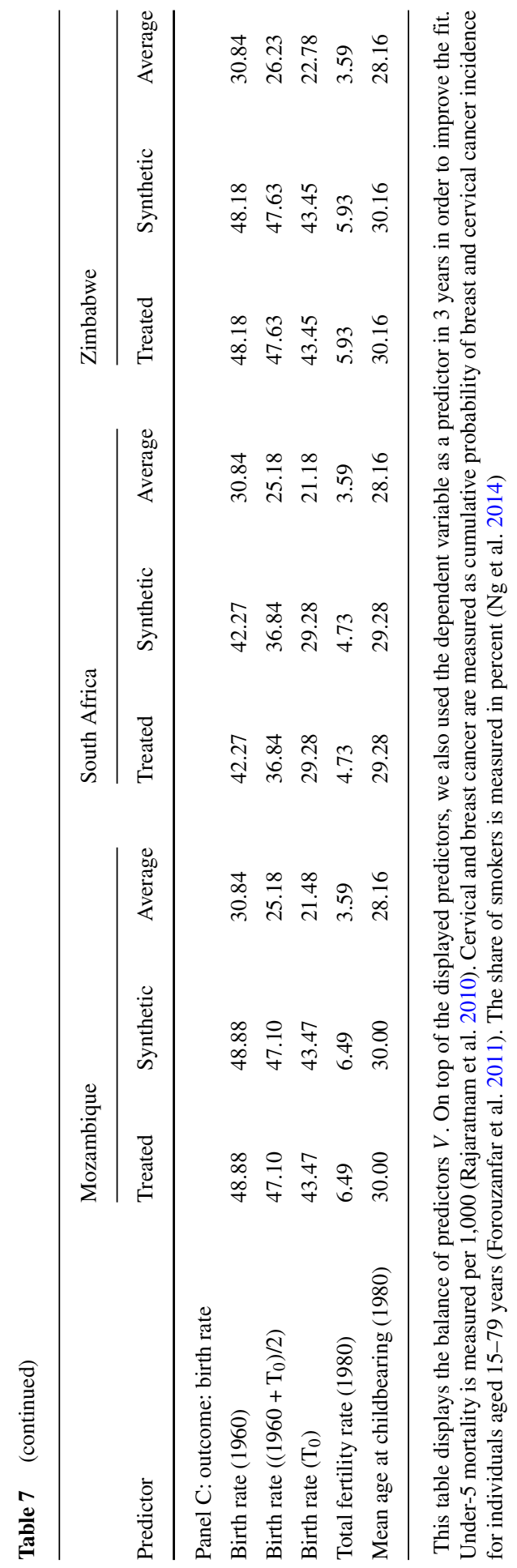


data source, the average smoker in Mozambique smoked less in 1980 than average smokers in the countries contributing to the synthetic control. Likewise, the average smoker in Zimbabwe smokes more than what smokers in the donor countries do (Ng et al. 2014). Thus, even though the discrepancies in the smoking prevalence rates are a notable exception from otherwise excellent matches, they might in fact overstate the differences in the public health burden represented by smoking behaviour in treated and control countries.

Conversely, it appears that the cancer mortality rates for cervical and breast cancer-which represented the greatest challenge in the African setting-can be much better replicated with this extended pool of donors. Deviations between treated and control units are less than 1/3 in all cases, and for South Africa they are virtually equal to zero.

\subsubsection{Results}

Also for the outcome variables themselves, we note an improvement in the fit when we relax the sample selection criteria. Results are presented in Table 8. In particular for the birth rate, the countries now perform uniformly better, but also for the other two outcomes do we note improvements in pre-treatment match. For example, the pre-treatment RMSPE for Zimbabwe is down to 0.19 from $4.29 \%$. South Africa

Table 8 Results for all donors

\begin{tabular}{|c|c|c|c|c|c|c|c|c|}
\hline & \multicolumn{2}{|l|}{ RMSPE } & \multicolumn{2}{|c|}{ RMSPE post } & \multicolumn{2}{|l|}{ MPE } & \multicolumn{2}{|l|}{ PE 2008} \\
\hline \multicolumn{9}{|c|}{ Panel A: life expectancy } \\
\hline & In logs & In years & In logs & In years & In logs & In years & In $\log s$ & In years \\
\hline Mozambique & $3.19 \%$ & 1.25 & $4.60 \%$ & 2.27 & $-3.36 \%$ & -1.64 & $-8.96 \%$ & -4.50 \\
\hline South Africa & $0.41 \%$ & 0.22 & $16.33 \%$ & 9.65 & $-13.31 \%$ & -7.90 & $-25.82 \%$ & -15.19 \\
\hline Zimbabwe & $0.22 \%$ & 0.12 & $29.83 \%$ & 15.99 & $-23.85 \%$ & -12.94 & $-39.94 \%$ & -21.84 \\
\hline \multicolumn{9}{|c|}{ Panel B: death rate } \\
\hline & In logs & In deaths & In $\log s$ & In deaths & In $\log s$ & In deaths & In $\log s$ & In deaths \\
\hline Mozambique & $4.71 \%$ & 1.17 & $5.41 \%$ & 0.87 & $2.79 \%$ & 0.43 & $9.79 \%$ & 1.49 \\
\hline South Africa & $3.05 \%$ & 0.38 & $59.05 \%$ & 5.64 & $50.29 \%$ & 4.70 & $91.56 \%$ & 9.12 \\
\hline Zimbabwe & $1.23 \%$ & 0.14 & $67.48 \%$ & 7.51 & $54.87 \%$ & 5.97 & $86.26 \%$ & 9.25 \\
\hline \multicolumn{9}{|c|}{ Panel C: birth rate } \\
\hline & In $\log s$ & In births & In $\log s$ & In births & In $\log s$ & In births & In logs & In births \\
\hline Mozambique & $1.58 \%$ & 0.71 & $7.27 \%$ & 2.97 & $6.25 \%$ & 2.56 & $6.44 \%$ & 2.44 \\
\hline South Africa & $1.09 \%$ & 0.40 & $1.69 \%$ & 0.42 & $-0.87 \%$ & -0.22 & $-3.51 \%$ & -0.79 \\
\hline Zimbabwe & $0.99 \%$ & 0.47 & $1.33 \%$ & 0.44 & $1.05 \%$ & 0.35 & $0.96 \%$ & 0.28 \\
\hline
\end{tabular}

This table shows the estimated effects for each country. The root mean square prediction error (RMSPE) is defined in Eq. 5. We calculate it before the intervention (column 2), and after (column 4). Column 6 reports the mean prediction error (MPE; see Eq. 6). Finally, we show the difference of the outcome variable in the final period (2008) in column 8. Results are provided in logarithmic scale and in the natural units, i.e. years of life expectancy and death and births per 1,000 inhabitants 
has similar improvements in the RMSPE. Indeed, both countries have now overtaken Mozambique and exhibit superior pre-treatment fit for two of the outcomes.

Despite these changes, however, the results remain very stable. There is a marked reduction in life expectancy for South Africa and Zimbabwe, and a corresponding increase in death rates by more than $50 \%$. Also the non-result for Mozambique carries over to this setting: the estimated effect on life expectancy and mortality is now slightly larger than in the previous specification, but still much lower than in the two other countries, and far lower than what one would expect. For birth rates, we again find very modest effects in all three countries.

Results from the placebo regressions are reported in Table 9. The first column reports the treatment year, the second column the treatment status, and then we report the pre- and post-treatment RMSPE. This variable does not take the sign of the effect

Table 9 Placebo results for all donors

\begin{tabular}{|c|c|c|c|c|c|c|c|}
\hline Country & Treatment year & Treated & RMSPE & RMSPE post & MPE & PE 2008 & Rank \\
\hline \multicolumn{8}{|c|}{ Panel A: outcome: life expectancy } \\
\hline Zimbabwe & 1985 & 1 & $0.22 \%$ & $29.83 \%$ & $-23.85 \%$ & $-39.94 \%$ & 1 \\
\hline South Africa & 1991 & 1 & $0.41 \%$ & $16.33 \%$ & $-13.31 \%$ & $-25.82 \%$ & 2 \\
\hline Senegal & 1991 & 0 & $1.25 \%$ & $8.42 \%$ & $-7.37 \%$ & $-12.86 \%$ & 3 \\
\hline El Salvador & 1987 & 0 & $2.28 \%$ & $8.24 \%$ & $8.00 \%$ & $8.13 \%$ & 4 \\
\hline Somalia & 1982 & 0 & $1.74 \%$ & $7.74 \%$ & $-6.09 \%$ & $-13.40 \%$ & 5 \\
\hline Belarus & 1991 & 0 & $1.49 \%$ & $6.97 \%$ & $-6.57 \%$ & $-9.59 \%$ & 6 \\
\hline Kazakhstan & 1988 & 0 & $0.22 \%$ & $6.31 \%$ & $-5.70 \%$ & $-7.89 \%$ & 7 \\
\hline Bosnia and Herzegovina & 1982 & 0 & $0.87 \%$ & $6.03 \%$ & $-4.75 \%$ & $-3.83 \%$ & 8 \\
\hline Nicaragua & 1985 & 0 & $0.95 \%$ & $5.98 \%$ & $5.38 \%$ & $8.29 \%$ & 9 \\
\hline Laos & 1982 & 0 & $0.25 \%$ & $5.26 \%$ & $4.82 \%$ & $5.31 \%$ & 10 \\
\hline \multicolumn{8}{|l|}{.. } \\
\hline Mozambique & 1990 & 1 & $3.19 \%$ & $4.60 \%$ & $-3.36 \%$ & $-8.96 \%$ & 14 \\
\hline \multicolumn{8}{|c|}{ Panel B: outcome: death rate } \\
\hline Zimbabwe & 1985 & 1 & $1.23 \%$ & $67.48 \%$ & $54.87 \%$ & $86.26 \%$ & 1 \\
\hline South Africa & 1991 & 1 & $3.05 \%$ & $59.05 \%$ & $50.29 \%$ & $91.56 \%$ & 2 \\
\hline Oman & 1983 & 0 & $8.19 \%$ & $45.60 \%$ & $-41.18 \%$ & $-40.14 \%$ & 3 \\
\hline Nicaragua & 1985 & 0 & $2.35 \%$ & $38.36 \%$ & $-34.96 \%$ & $-53.51 \%$ & 4 \\
\hline Costa Rica & 1991 & 0 & $13.94 \%$ & $34.10 \%$ & $-33.28 \%$ & $-19.69 \%$ & 5 \\
\hline Kazakhstan & 1988 & 0 & $2.49 \%$ & $31.71 \%$ & $28.32 \%$ & $34.39 \%$ & 6 \\
\hline Somalia & 1982 & 0 & $3.42 \%$ & $26.84 \%$ & $21.38 \%$ & $45.66 \%$ & 7 \\
\hline China & 1987 & 0 & $16.70 \%$ & $21.05 \%$ & $20.21 \%$ & $33.57 \%$ & 8 \\
\hline Bhutan & 1991 & 0 & $1.50 \%$ & $20.37 \%$ & $-18.40 \%$ & $-28.17 \%$ & 9 \\
\hline Qatar & 1991 & 0 & $18.74 \%$ & $19.72 \%$ & $-15.90 \%$ & $-38.98 \%$ & 10 \\
\hline \multicolumn{8}{|l|}{..} \\
\hline Mozambique & 1990 & 1 & $4.71 \%$ & $5.41 \%$ & $2.79 \%$ & $9.79 \%$ & 69 \\
\hline
\end{tabular}


Table 9 (continued)

\begin{tabular}{|c|c|c|c|c|c|c|c|}
\hline Country & Treatment Year & Treated & RMSPE & RMSPE post & MPE & PE 2008 & Rank \\
\hline \multicolumn{8}{|c|}{ Panel C: outcome: birth rate } \\
\hline Iran & 1987 & 0 & $3.91 \%$ & $52.88 \%$ & $-48.56 \%$ & $-67.11 \%$ & 1 \\
\hline Mongolia & 1982 & 0 & $0.99 \%$ & $40.85 \%$ & $-32.86 \%$ & $-57.24 \%$ & 2 \\
\hline Somalia & 1982 & 0 & $1.42 \%$ & $29.94 \%$ & $25.28 \%$ & $40.13 \%$ & 3 \\
\hline United States & 1985 & 0 & $3.34 \%$ & $28.48 \%$ & $25.26 \%$ & $26.31 \%$ & 4 \\
\hline Iceland & 1987 & 0 & $6.86 \%$ & $27.41 \%$ & $26.33 \%$ & $42.43 \%$ & 5 \\
\hline Latvia & 1991 & 0 & $11.63 \%$ & $23.17 \%$ & $-21.99 \%$ & $-14.55 \%$ & 6 \\
\hline Denmark & 1987 & 0 & $5.67 \%$ & $22.91 \%$ & $21.47 \%$ & $21.60 \%$ & 7 \\
\hline Germany & 1985 & 0 & $14.86 \%$ & $22.58 \%$ & $-21.19 \%$ & $-32.25 \%$ & 8 \\
\hline Argentina & 1983 & 0 & $6.20 \%$ & $21.92 \%$ & $18.02 \%$ & $17.29 \%$ & 9 \\
\hline Lithuania & 1990 & 0 & $6.26 \%$ & $21.21 \%$ & $-18.49 \%$ & $-16.06 \%$ & 10 \\
\hline .. & & & & & & & \\
\hline $\begin{array}{l}\text { Mozambique } \\
\text {.. }\end{array}$ & 1990 & 1 & $1.58 \%$ & $7.27 \%$ & $6.25 \%$ & $6.44 \%$ & 58 \\
\hline $\begin{array}{l}\text { South Africa } \\
\text {.. }\end{array}$ & 1991 & 1 & $1.09 \%$ & $1.69 \%$ & $-0.87 \%$ & $-3.51 \%$ & 85 \\
\hline Zimbabwe & 1985 & 1 & $0.99 \%$ & $1.33 \%$ & $1.05 \%$ & $0.96 \%$ & 87 \\
\hline
\end{tabular}

This table shows the estimated effects for each country. We distinguish treated countries (HIV prevalence $\geq 10 \%$ ) and placebo countries (HIV prevalence $\leq 1 \%$ ). The RMSPE is defined in Eq. 5. We calculate it before the intervention (column 4) and afterwards (column 5); the countries are ranked by the latter. Column 6 is calculated using (6). In column 7, we show the difference of the outcome variable in the final period (2008)

into account, and for this reason, we also report the mean prediction error and the prediction error in 2008. A total of 94 countries are included in the placebo analysis and for an overwhelming majority of them, we get a very good pre-treatment fit for all three outcome variables.

The top panel reports results for life expectancy. A graphical representation of the results may be found in Fig. 1. For this outcome, South Africa and Zimbabwe have by far the largest deviations from their synthetic control groups-irrespective of whether the RMSPE, the MPE or the PE2008 is used for ranking, and irrespective of whether the sign of the effect is considered or not. Thus, the answer to the question regarding statistical significance of those two countries is a resounding yes. A more intricate issue is whether our method has any power at modest effect sizes. When considering the distribution of post-treatment RMSPE, an estimate of around $8 \%$ would have been deemed significant within the overall pool of countries. This is less than half than the estimate for South Africa and only a fourth of the effect estimated for Zimbabwe. The result is similar if one considers the alternative metrics such as MPE or PE2008. Thus, we conclude that given the good pre-treatment fit for donors and treated countries alike, the method is quite powerful also at relatively modest 

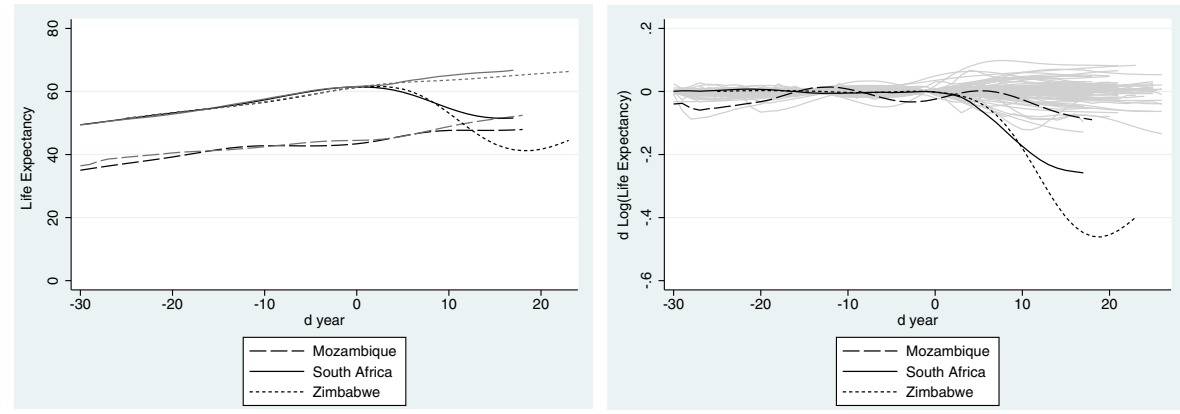

Fig. 1 Results and placebos: life expectancy

effect sizes, and that the non-result for Mozambique thus seems not to be attributable to poor performance of the method. Finally, we consider the three countries as a group and test their joint significance in accordance with the statistic given in Eq. 7. In a two-sided test based on the RMSPE, the rankings of the three countries $(1,2,14)$ would be associated with a $p$ value of less than 0.001 .

Not surprisingly, the results for death rates come out quite similar to those for life expectancy (cf. Table 9 panel B and Fig. 2): Zimbabwe and South Africa come out on top irrespective of the metric used, and irrespective of whether the sign of the estimated effect is taken into account or not. Thus, regarding the significance of these two countries, we draw the same conclusions as above. As regards the minimum detectable effect size, it appears that a post-treatment RMSPE of around $40 \%$ is the smallest effect size that would be deemed significant. This is, again, much lower than the effects observed for Zimbabwe $(67.5 \%)$ and South Africa (59 \%) but still more than one would wish in order to draw clear inference. This loss in precision seems to be partly attributable to the pre-treatment fit being much worse for some countries in the donor pool-7 of the 94 countries have a pre-treatment RMSPE above $10 \%$-but this is not the only reason: estimates for the death rate seem to be noisier in general.
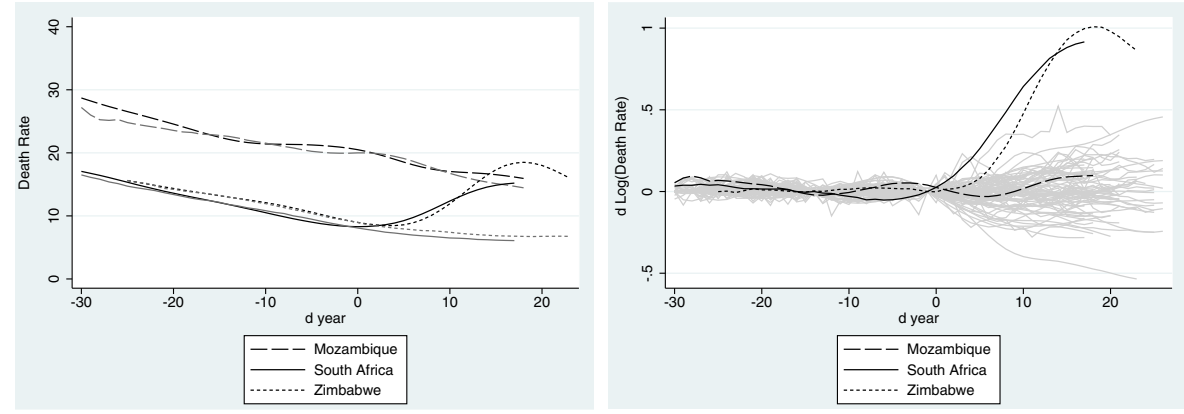

Fig. 2 Results and placebos: death rate 
Nevertheless, we conclude that there is consistent evidence of a large increase in death rates in South Africa and Zimbabwe, whereas the evidence for Mozambique suggests that the HIV pandemic has had only a limited effect on mortality. Again, we test the joint significance based on Eq. 7. The $p$ value associated with rankings $(1,2,69)$ is again less than 0.001 .

Concerning the birth rate, finally, we conclude that there are no significant changes for any of the three countries taken individually or as a whole (cf. Table 9 panel $\mathrm{C}$ and Fig. 3). Relating this to the ongoing debate about the effect of HIV on fertility, we believe that our results show that HIV has no discernible effect on fertility, and for two reasons we have confidence in our estimates. Firstly, the pre-treatment fit of the outcome variable and for covariates was very good for this outcome, for all three countries. Secondly, the spread in placebo estimates for this variable is relatively limited and thus, a change with a magnitude of around $20 \%$ (in RMSPE terms) would already have been considered significant. This comparably limited spread in placebo estimates is not, however, driven by the variable itself exhibiting less variation over time and between countries (which should become clear from a comparison of the three outcomes between countries and over time in Table 7).

\subsection{Discussion}

Our results so far can be summarised as follows: there is strong and consistent evidence that the pandemic had a large negative effect on life expectancy and a corresponding positive effect on mortality rates in Zimbabwe and South Africa, whereas the effect of the pandemic appears to have been surprisingly small in Mozambique. As regards fertility, our results suggest that any effect of the pandemic has been limited in all three countries. We will now try to understand what is driving these results, and in particular the results regarding life expectancy.

As regards mortality and life expectancy, our investigation will be conducted in three steps. In a first step, we consider if and how the covariates used for matching have diverged between treated countries and their synthetic controls. However, there are much better data available for the post-treatment period, so we also consider some additional variables which are available from later years, in particular mortality by
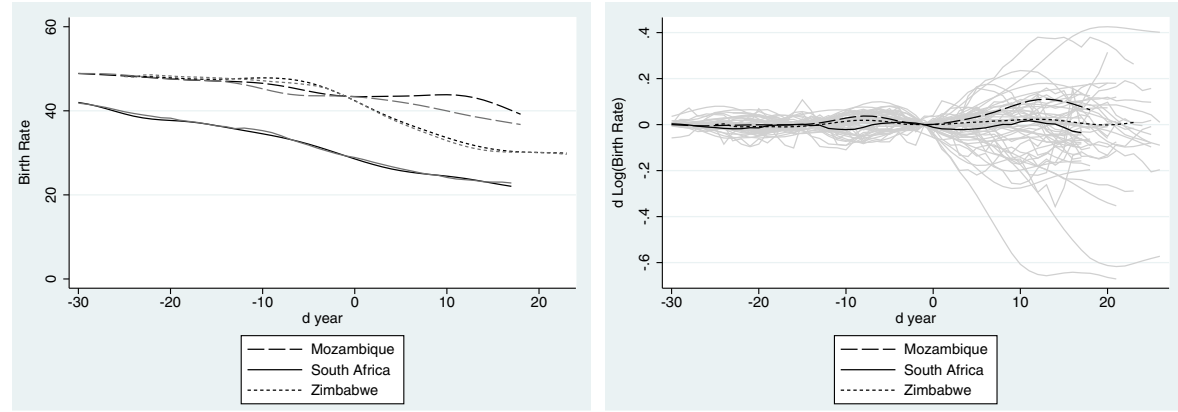

Fig. 3 Results and placebos: birth rate 
death cause. In the 2004 Global Burden of Disease Study, published by the World Health Organization (2004), mortality rates by death cause were provided for all WHO member states. These estimates were based on national statistics and analyses by the WHO. The population at risk was taken from official UN population estimates, and the death causes were classified according to ICD-9.

We will use these data to answer the question of whether the diverging results between the three countries are attributable to differences in HIV mortality rates, or to differences in mortality due to other causes.

In Table 10, we present a comparison of the 2002 values of the covariates used in our analysis. We present the actual value, the value observed in the synthetic control group in the same year and the difference between the two for each of the three countries. Interestingly, the table suggests that the synthetic controls exhibit covariate balance for most of the variables considered also several years after treatment. Thus, it becomes clear from this table that the prevalence of cancer and of smoking cannot be driving our results. Only for the under-5 mortality rate do we find some evidence which might explain some of the heterogeneity in impact: in Mozambique and South Africa, the under-5 mortality rate appears to be completely unaffected by the pandemic, whereas Zimbabwe does register an elevated under-5 mortality rate. All three countries experienced a marked reduction in IMR over the 30-year period considered, but in Zimbabwe, the reduction was apparently smaller than one would have expected given the starting position.

Next, we turn to a comparison of death causes in the same year. Estimates are presented in Table 11. Again, we provide a comparison between the treated countries and their synthetic controls. The top row presents all-cause mortality, and it is thus equivalent to our death rate outcome variable. Accordingly, the HIV pandemic was associated with a mortality burden of 1,521 additional deaths per 100,000 in Zimbabwe, 600 in South Africa and 244 additional deaths in Mozambique. In the same year, the HIV prevalence rate was 24.4 in Zimbabwe, 17.6 in South Africa and $11 \%$ in Mozambique. Thus, the overall death toll is not proportional to the prevalence of the disease: Zimbabwe had a 2.2 times higher prevalence rate, but a six times higher death toll than Mozambique.

The pattern for HIV-related deaths is, however, slightly different: for this variable, Zimbabwe's death toll equals 1,403, South Africa's 787 and Mozambique's 548.

Table 10 Life expectancy covariates in 2002

\begin{tabular}{|c|c|c|c|c|c|c|c|c|c|}
\hline \multirow[b]{2}{*}{ Variable } & \multicolumn{3}{|c|}{ Mozambique } & \multicolumn{3}{|c|}{ South Africa } & \multicolumn{3}{|c|}{ Zimbabwe } \\
\hline & Real & Synthetic & Diff. & Real & Synthetic & Diff. & Real & Synthetic & Diff. \\
\hline Under-5 mortality & 163.5 & 162.2 & 1.3 & 37.3 & 36.7 & 0.6 & 73.7 & 43.4 & 30.3 \\
\hline Cervical cancer & 4.9 & 3.6 & 1.3 & 3.9 & 3.2 & 0.7 & 6.5 & 4.9 & 1.6 \\
\hline Breast cancer & 2.9 & 2.0 & 0.9 & 5.1 & 3.8 & 1.3 & 5 & 3.4 & 1.6 \\
\hline Share of smokers & 6.4 & 4.3 & 2.1 & 14.6 & 14.0 & 0.6 & 6.3 & 9.3 & -3.1 \\
\hline
\end{tabular}

This table shows the 2002 values of the covariates used in the matching algorithm for life expectancy 


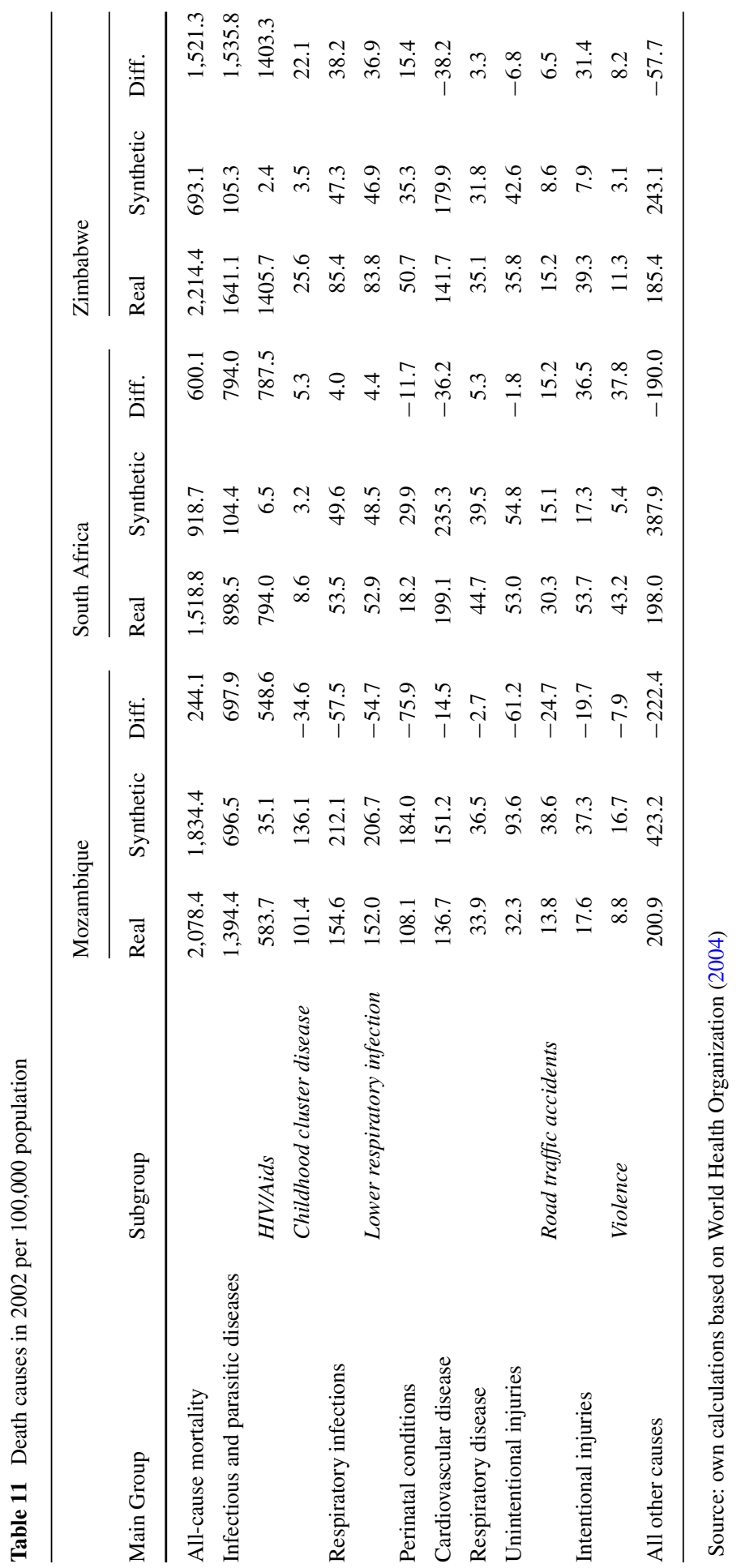


Hence, we may rule out that the estimated effect heterogeneity is attributable to the disease taking a different course in the three countries: the number of HIV deaths is approximately proportional to the prevalence rate.

However, the table also makes clear that Mozambique exhibits lower mortality rates than expected for some other death causes, and it appears to be this reduced mortality due to other causes which explains the discrepancy between the HIV-related mortality and all-cause mortality. We have listed some of the leading death causes in the table, and it becomes immediately evident that some of them counteract the direct effect of HIV/AIDS. This is most evident regarding some death causes which occur early in life such as childhood cluster disease and perinatal conditions. These two conditions combined are responsible for 210 fewer deaths per 100,000 in Mozambique compared to its synthetic control. There is no comparable pattern for the other two countries. Hence, the result we reported above, that Mozambique's under-5 mortality rate is unaffected by the pandemic, seems to be the result of HIV and other death causes cancelling out.

The next question to ask, then, is if this reduction in other death causes is somehow related to the pandemic. We believe this to be the case. The quality of data from Sub-Saharan Africa clearly limits the quality of the evidence that may be presented to support this story, but we will now provide some facts which seem to support our view.

First, as regards neonatal mortality and childhood cluster disease, it appears that breastfeeding patterns are important for gaining an understanding of how the pandemic operates. The benefits for infant health of breastfeeding are well-established in the literature. Breastfeeding has been shown to reduce the risk of several health hazards, such as asthma, diarrhoea, lower respiratory infections, diabetes and sudden infant death syndrome (Miotti et al. 1999; Victoria et al. 2000; Duijts et al. 2010). In 2001, the World Health Assembly endorsed a recommendation that infants should be exclusively breastfed during the first 6 months of life, and thereafter exposed to breastfeeding mixed with other foods for at least 18 additional months (World Health Organization 2003).

However, the presence of HIV complicates the issue and creates a trade-off between the above-mentioned beneficial effects and an elevated risk of mother-tochild transmission of HIV. Each year, hundreds of thousands of children are infected with HIV, and the reason is almost always a transmission from mother to child. For an HIV-positive mother, the overall transmission rate has been estimated at 30$45 \%$, and between one-third and one-half of those transmissions may be attributed to breastfeeding (World Health Organization 2008). ${ }^{5}$ The risk associated with breastfeeding is roughly constant during the breastfeeding period, and the cumulative risk thus increases linearly with each month of breastfeeding. Finally, the mortality rates of HIV-infected infants are very high (Newell et al. 2004).

\footnotetext{
${ }^{5}$ The availability of antiretroviral drugs is likely to have reduced these rates significantly in recent years (Rollins et al. 2013).
} 
A study from South Africa has shown that exclusive breastfeeding is less risky than mixed feeding ( $25 \%$ versus $36 \%$ ) but formula feeding is obviously less risky than both (1\%; Coovadia et al. 2007). Several studies from other countries have since confirmed this result, which has motivated the WHO to issue a qualified recommendation for HIV-positive mothers: exclusive breastfeeding is still recommended during the first 6 months of life, unless a replacement is acceptable, feasible and affordable (World Health Organization 2008). These recommendations have later been changed in the wake of ARV therapy, but the new recommendations from 2009 fall outside the observation window of this study (World Health Organization 2010a).

The countries analysed in this study-Mozambique. South Africa and Zimbabwe-have different traditions regarding breastfeeding, and they have also reacted differently to the pandemic. South Africa and Zimbabwe both have amongst the lowest rates of exclusive breastfeeding in the world: for South Africa, the level has been reported at $8 \%$ (World Health Organization 2009), and a recent survey in Zimbabwe puts the rate at $6 \%$ (Food and Nutrition Council 2010). In contrast, Mozambique performs very well according to the 2010 WBTi report (World Health Organization 2010b), and exclusive breastfeeding rates are above $40 \%$ (World Health Organization 2009). Likewise, there is evidence that the trends have been diverging in the three countries: for South Africa, the "ever breastfeeding" rates went down from 88 to $81 \%$ between 1994 and 2004, whereas they increased from 94 to $98 \%$ in Mozambique between 1997 and 2003 (World Health Organization 2009 the corresponding numbers for Zimbabwe are inconclusive). These trends in "ever breastfeeding" rates are mirrored by trends in exclusive breastfeeding: for Mozambique, the rate has increased by 10 percentage points since the turn of the century (World Health Organization 2009).

Thus, it appears that breastfeeding practices may be one reason why the pandemic has had such a differential impact in the three countries: in Mozambique, the pandemic coincides with an improved adherence to WHO breastfeeding recommendations, whereas practices seem to have been unaffected or even worsening in South Africa. Indeed, against the backdrop of worryingly high under-5 mortality rates, the South African government announced a change in policies in 2011, committing to promoting an exclusive breastfeeding policy (Bloemen 2012).

In a similar fashion, (road) accidents provide another competing risk on which the HIV pandemic may have had an indirect effect. According to Lagarde (2007), road accidents are an important risk, especially in the African context. All three countries in our study experience relatively high fatality rates in an international comparison, and their tendency has been increasing. The incidence of road traffic fatalities is dwarfed by HIV mortality in all three countries-as visible in Table 11-but they are heavily concentrated in the middle-aged groups between 20 and 40 (Statistics South Africa 2013). This is, incidentally, the age group that is responsible for the majority of HIV-related deaths, and who enjoy very low mortality rates in countries not affected by the pandemic (Division Population 2012). A reduction in road traffic fatalities due to the AIDS pandemic would thus be expected-but in fact we only observe this pattern for Mozambique.

Thus, there is some evidence to suggest that the reductions in mortality which we observe for some causes may be causally linked to the pandemic. To some 
extent, as in the case of breastfeeding, the heterogeneous impact between the three countries may be attributable to behavioural changes. However, there is also an automatic mechanism operating: whenever a new death cause enters the picture, it will inevitably be associated with a reduction in the mortality rates associated with other causes. The consequence is that the death cause statistics always overestimate the net effect of a pandemic. Moreover, this inherent bias will be larger, the higher the mortality rates were at the outset. Thus, a more general answer to the question why Mozambique follows a different trajectory may be found in Figs. 1 and 2. The most striking difference between Mozambique and the other two countries is that the death rate is twice as high as compared to South Africa and Zimbabwe. Similarly, life expectancy is about 10 years lower, already before the emergence of HIV. Therefore, our results suggest that if the death rate is already high to start with, then HIV will only have a modest effect on the overall death rate, while there is displacement in terms of causes of death.

Finally, we present some additional evidence for the birth rates. For this outcome, our main result was that there was no clear effect of the pandemic. In Table 12, we present some additional comparisons for 2002. In the top rows of the Table, we compare the 2002 values for the two covariates included in the matching procedurethe total fertility rate and the main age at childbearing. These two variables were perfectly matched in the pre-treatment period. Considering the situation in 2002, we see that not much has changed: the countries have experienced small reductions in the total fertility rates, but the difference between the treated countries and their synthetic controls remain small. Similarly for the mean age at child bearing, we only observe a small decrease in Zimbabwe relative to its synthetic control.

Next, we tabulate the fertility rates by age group. These variables were not used in the matching procedure so there is no guarantee that they should balance; however,

Table 12 Birthrate covariates in 2002

\begin{tabular}{|c|c|c|c|c|c|c|c|c|}
\hline \multirow[b]{2}{*}{ Variable } & \multicolumn{2}{|l|}{ Mozambique } & \multicolumn{3}{|c|}{ South Africa } & \multicolumn{3}{|c|}{ Zimbabwe } \\
\hline & Real Synthetic & Diff. & Real & Synthetic & Diff. & Real & Synthetic & Diff. \\
\hline
\end{tabular}

Panel A: variables used in the matching algorithm

$\begin{array}{lrrrrrrrrr}\text { Total fertility rate } & 5.5 & 5.6 & 0.0 & 2.8 & 3.2 & -0.4 & 3.9 & 4.2 & -0.3 \\ \text { Mean age at childbearing } & 28.8 & 28.8 & 0.0 & 28.8 & 28.3 & 0.5 & 28.2 & 30.5 & -2.3 \\ \text { Panel B: age-specific fertility rates (not used in the matching algorithm) } & & & & \\ \text { y1519 } & 179.0 & 116.5 & 62.5 & 63.6 & 37.4 & 26.2 & 103.3 & 36.5 & 66.8 \\ \text { y2024 } & 246.0 & 265.4 & -19.4 & 125.4 & 128.2 & -2.8 & 203.0 & 143.2 & 59.8 \\ \text { y2529 } & 226.0 & 252.5 & -26.5 & 139.6 & 160.8 & -21.2 & 174.7 & 194.2 & -19.5 \\ \text { y3034 } & 191.0 & 190.4 & 0.6 & 117.4 & 133.8 & -16.4 & 141.0 & 191.7 & -50.7 \\ \text { y3539 } & 148.0 & 138.8 & 9.2 & 74.4 & 77.0 & -2.6 & 93.3 & 134.0 & -40.7 \\ \text { y4044 } & 75.0 & 65.6 & 9.4 & 30.2 & 27.4 & 2.8 & 43.3 & 58.9 & -15.6 \\ \text { y4549 } & 43.0 & 10.1 & 32.9 & 9.4 & 3.0 & 6.4 & 13.7 & 17.2 & -3.5\end{array}$

This table shows the 2002 values of the covariates used in the matching algorithm for the birth rate. Source: own calculation based on Nations United (2013) 
if TFR, birthrates and mean age at childbearing are balanced-these age-specific variables are likely to be closely aligned as well.

For all three countries, we observe a slight increase in fertility at very young ages (15-19), and a decrease at older ages. However, we find no overall evidence that the pandemic has led to a change in fertility patterns: the synthetic control closely mirrors the treated country in most age groups.

\section{Conclusion}

In this paper, we have estimated the effects of the HIV pandemic on life expectancy, mortality and birth rates in three heavily affected countries in Sub-Saharan Africa. Using the synthetic control group approach (Abadie and Gardeazabal 2003), we find suitable control groups for Mozambique, South Africa and Zimbabwe.

A first main result of this paper is that the method, which has not previously been used in this context, appears to be highly suitable for the analysis of the effects of HIV. Even the restricted donor pool of African countries with high-quality demographic information allows building synthetic controls which exhibit reasonable covariate balance and pre-treatment fit of the respective outcome variables. When we allow for donors also from other parts of the world, the performance of the estimator improves further, but results remain strikingly robust compared with the previous specification.

Just as expected, our results indicate that the HIV pandemic has had a large effect on life expectancy and death rates. For Zimbabwe, the most heavily affected country in the group, the reduction in life expectancy is as large as $24 \%$ on average in the post-treatment period ( $40 \%$ in the final year). However, even though we find that the effect in the three countries is jointly highly significant, there are striking differences between them: according to our estimates, there is hardly any effect in Mozambique, despite a prevalence rate well over $10 \%$. In our preferred specification, the reduction in life expectancy is estimated to be $3.4 \%$, and the corresponding increase in death rates is even less than $3 \%$.

In order to shed some light on this surprising result, we turned to WHO statistics on death causes. Based on this information, we can rule out the possibility that the epidemic is less virulent in Mozambique than elsewhere: the number of HIV-related deaths is as high as expected given the prevalence rates. Instead, the explanation seems to be that Mozambique has an unexpectedly low mortality rate for some other death causes. The most prominent examples we find are death causes which affect children - and which thus disproportionately reduce life expectancybut also respiratory infections and injuries seem to have relatively low prevalence in Mozambique.

It goes beyond the scope of this paper to provide an answer to the question why we observe these countervailing trends in Mozambique - and the poor data availability in these countries would make it challenging to find a definite answer. Still, it is our tentative conclusion that these trends are to some extent a result of the pandemic. In terms of life expectancy, Mozambique had a much worse starting position than the two other countries - and so it was to be expected that the net effect of the pandemic 
was going to be smaller here than elsewhere. Moreover, we have identified divergent trends in breastfeeding between the three countries, which may be one additional reason why the effects on child mortality are different in Mozambique. In summary, a main implication of our paper is that the demographic impact of the HIV pandemic may be different from what aggregate prevalence rates or HIV-related mortality rates suggest - and that an informed assessment needs to take the general situation in the country into account.

We have also addressed the ongoing debate regarding the impact of the HIV pandemic on birthrates. For this variable, our main results are that the overall effect of HIV on fertility appears to be very limited.

Acknowledgments We would like to thank Emily Oster for making HIV prevalence data available. Moreover, we thank Annika Lindskog for excellent comments and Christian Brückner for research assistance. Finally, we thank two anonymous referees for their help and guidance. We take responsibility for all remaining errors in and shortcomings of the article.

\section{References}

Abadie A, Diamond A, Hainmueller J (2010) Synthetic control methods for comparative case studies: Estimating the effect of California's tobacco control program. J Am Stat Assoc 105(490):493505

Abadie A, Gardeazabal J (2003) The economic costs of conflict: a case study of the Basque Country. The Am Econ Rev 93(1):113-132

Arrehag L, De Vylder S, Durevall D, Sjöblom M (2006) The impact of HIV/AIDS on livelihoods, poverty and the economy of Malawi Sida Studies no 18

Becker G, Murphy K, Tamura R (1990) Economic growth, human capital and population growth. J Political Econ 98(5):S12-S137

Bell C, Devarajan S, Gersbach H (2006) The long-run economic costs of AIDS: a model with an application to South Africa. The World Bank Econ Rev 20(1):55

Bloemen S (2012) In a major policy shift, mothers in South Africa are encouraged to exclusively breastfeed instead of using formula. Unicef Newsline

Bloom D, Mahal A (1997) Does the AIDS epidemic threaten economic growth. J Econ 77(1):105-124

Bloom D, Sachs J, Collier P, Udry C (1998) Geography, demography, and economic growth in Africa. Brook Pap Econ Act 1998(2):207-295

Bongaarts J, Pelletier F, Gerland P (2010) How many more AIDS deaths. The Lancet 375(9709):103-104

Booysen F (2006) Out-migration in the context of the HIV/AIDS epidemic: evidence from the Free State province. J Ethn Migr Stud 32(04):603-631

Chen H (2010) Life expectancy, fertility, and educational investment. J Popul Econ 23(1):37-56

Coovadia HM, Rollins NC, Bland RM, Little K, Coutsoudis A, Bennish ML, Newell M-L (2007) Motherto-child transmission of HIV-1 infection during exclusive breastfeeding in the first 6 months of life: an intervention cohort study. The Lancet 369(9567):1107-1116

Cutler D, Deaton A, Lleras-Muney A (2006) The determinants of mortality. The J Econ Perspect 20(3):97120

Deaton A (2008) Income, health and wellbeing around the world: evidence from the Gallup World Poll. The J Econ Perspect 22(2):53

Decosas J, Adrien A (1996) Migration and HIV. AIDS (London England) 11:S77—84

Duijts L, Jaddoe VW, Hofman A, Moll HA (2010) Prolonged and exclusive breastfeeding reduces the risk of infectious diseases in infancy. Pediatrics 126(1):e18-e25

Durevall D, Lindskog A (2011) Uncovering the impact of the HIV epidemic on fertility in Sub-Saharan Africa: the case of Malawi. J Popul Econ 24(2):629-655

Ellis M, Muschkin C (1996) Migration of persons with AIDS: search for support from elderly parents. Soc Sci \& Med 43(7):1109-1118 
Fabiani M, Nattabi B, Ayella E, Ogwang M, Declich S (2006) Differences in fertility by HIV serostatus and adjusted HIV prevalence data from an antenatal clinic in northern Uganda. Trop Med \& Int Health 11(2):182-187

Fink G, Linnemayr S (2008) HIV education and fertility: long term evidence from Sub-Saharan Africa Working paper. Harvard School of Public Health

Fogel R (2004) The escape from hunger and premature death, 1700-2100: Europe, America, and the Third World. Vol. 38. Cambridge University Press

Food and Nutrition Council (2010) Zimbabwe National Nutrition Survey 2010 Ministry of Health and Child Welfare

Forouzanfar MH, Foreman KJ, Delossantos AM, Lozano R, Lopez AD, Murray CJ, Naghavi M (2011) Breast and cervical cancer in 187 countries between 1980 and 2010: a systematic analysis. The Lancet 378(9801):1461-1484

Fortson J (2009) HIV/AIDS and fertility. Am Econ J Appl Econ 1(3):170-194

Fortson JG (2011) Mortality risk and human capital investment: the impact of HIV/AIDS in Sub-Saharan Africa. The Rev Econ Stat 93(1):1-15

Frankema E, Jerven M (2014) Writing history backwards or sideways: towards a consensus on African population, 1850-2010. The Econ History Rev 67:907-931

Fung K, Krewski D, Burnett R, Dominici F (2005) Testing the harvesting hypothesis by time-domain regression analysis. J Toxicol Environ Health Part A 68(13-14):1137-1154

Gaffeo E (2003) The economics of HIV/AIDS: a survey. Dev Policy Rev 21(1):27-49

Gregson S, Garnett GP, Nyamukapa CA, Hallett TB, Lewis JJ, Mason PR, Chandiwana SK, Anderson RM (2006) HIV decline associated with behavior change in eastern Zimbabwe. Sci 311(5761):664-666

Hinrichs P (2012) The effects of affirmative action bans on college enrollment, educational attainment, and the demographic composition of universities. Rev Econ Stat 94(3):712-722

Iliffe J (2006) A history of the African AIDS epidemic Athens. Ohio University Press

Juhn C, Kalemli-Ozcan S, Turan B (2013) HIV and fertility in Africa: first evidence from population based surveys. J Popul Econ 26(3):835-853

Kalemli-Ozcan S (2012) AIDS, reversal of the demographic transition and economic development: evidence from Africa. J Popul Econ 25(3):871-897

Karlsson M, Nilsson T, Pichler S (2014) The impact of the 1918 Spanish flu epidemic on economic performance in Sweden: an investigation into the consequences of an extraordinary mortality shock. J Health Econ 36:1-19

Lagarde E (2007) Road traffic injury is an escalating burden in Africa and deserves proportionate research efforts. PLoS Med 4(6):170

Lurie MN (2006) The epidemiology of migration and HIV/AIDS in South Africa. J Ethn Migr Stud 32(4):649-666

Manning P (2010) African Population Projections, 1850-1960. Ohio University Press

McNeill W (2010) Plagues and peoples Random House Digital Inc

Mesnard A, Seabright P (2009) Escaping epidemics through migration? Quarantine measures under incomplete information about infection risk. J Public Econ 93(7):931-938

Miotti PG, Taha TE, Kumwenda NI, Broadhead R, Mtimavalye LA, Van der Hoeven L, Chiphangwi JD, Liomba G, Biggar RJ (1999) HIV transmission through breastfeeding: a study in Malawi. The J Am Med Assoc (JAMA) 282(8):744-749

Montalvo J (2011) Voting after the bombings: a natural experiment on the effect of terrorist attacks on democratic elections. Rev Econ Stat 93(4):1146-1154

Newell M-L, Coovadia H, Cortina-Borja M, Rollins N, Gaillard P, Dabis F (2004) Mortality of infected and uninfected infants born to HIV-infected mothers in Africa: a pooled analysis. The Lancet 364(9441):1236-1243

$\mathrm{Ng} \mathrm{M}$, Freeman M, Fleming T et al (2014) Smoking prevalence and cigarette consumption in 187 countries, 1980-2012. The J Am Med Assoc (JAMA) 311(2):183-192

OECD (2005) Trends in International Migration Annual Report 2004 Paris OECD

Oster E (2012) Routes of infection: exports and HIV incidence in Sub-Saharan Africa. J Eu Econ Assoc 10(5):1025-1058

Division Population (2012) World mortality report 2011 United Nations Department of Economic and Social Affairs

Rajaratnam JK, Marcus JR, Flaxman AD, Wang H, Levin-Rector A, Dwyer L, Costa M, Lopez AD, Murray CJ (2010) Neonatal, postneonatal, childhood, and under-5 mortality for 187 countries, 
1970-2010: a systematic analysis of progress towards millennium development goal 4. The Lancet 375(9730):1988-2008

Rollins NC, Ndirangu J, Bland RM, Coutsoudis A, Coovadia HM, Newell M-L (2013) Exclusive breastfeeding, diarrhoeal morbidity and all-cause mortality in infants of HIV-infected and HIV uninfected mothers: an intervention cohort study in KwaZulu Natal, South Africa. PloS one 8(12):e81307

Rosling H (2014) Total population for countries and territories. Gap Minder dataset retrieved from Accessed 18 May 2014. http://www.gapminder.org/data/

Shapira G (2013) How subjective beliefs about HIV infection affect life-cycle fertility: evidence from rural Malawi. Policy Research Working Paper 6343 The World Bank Development Research Group Human Development and Public Services Team

Siegel S (1956) The Mann-Whitney U test Nonparametric Statistics for the Behavioral Sciences

Soskolne V, Shtarkshall RA (2002) Migration and HIV prevention programmes: linking structural factors, culture, and individual behaviour: an Israeli experience. Soc Sci \& Med 55(8):1297-1307

Statistics South Africa (2013) Mortality and causes of death in South Africa, 2010: Findings from death notification. Statistical release P0309.3, Statistics South Africa

The World Bank (2011) World development indicators The Wold Bank IEC information Center Development data group

UN Population Division (2004) The Impact of AIDS. Economic and social analysis of technology. United Nations

UNAIDS (2013) AIDS by the numbers

UNDP (2013) Trends in International Migrant Stock: migrants by destination and origin United Nations Department of Economic and Social Affairs

Nations United (2013) World Fertility Data 2012 United Nations Department of Economic and Social Affairs Population Division

Victoria C et al (2000) Effect of breastfeeding on infant and child mortality due to infectious diseases in less developed countries: a pooled analysis. Lancet (British edition) 355(9202):451-455

World Health Organization (2003) Global strategy for infant and young child feeding

World Health Organization (2004) The World Health Report 2004 Changing History. World Health Organization

World Health Organization (2008) HIV transmission through breastfeeding: a review of available evidence: 2007 update World Health Organization Geneve

World Health Organization (2009) Global data bank on infant and young child feeding

World Health Organization (2010a) Guidelines on HIV and infant feeding 2010: principles and recommendations for infant feeding in the context of HIV and a summary of evidence World Health Organization, Geneva, Switzerland

World Health Organization (2010b) The state of breastfeeding in 33 countries. World Health Organization

World Health Organization (2014) The top ten causes of death-fact sheet n310 World Health Organization Geneva

Young A (2005) The gift of the dying: the tragedy of AIDS and the welfare of future African generations. Quart J Econ 120(2):423-466

Young A (2007) In sorrow to bring forth children: fertility amidst the plague of HIV. J Econ Growth 12(4):283-327

Zuberi T, Bangha MW (2006) The history and future of African census analysis project LouvainCensuses New trends, new formulas 